\title{
Infrared spectra of pyrazine, pyrimidine and pyridazine in solid argon
}

\author{
S. Breda ${ }^{\text {a }}$, I.D. Reva ${ }^{\text {a }}$, L. Lapinski ${ }^{\text {a,b }}$, M.J. Nowak ${ }^{\text {b }}$, R. Fausto ${ }^{\text {a,* }}$ \\ a Department of Chemistry, University of Coimbra, Coimbra P-3004-535, Portugal \\ ${ }^{\mathrm{b}}$ Institute of Physics, Polish Academy of Sciences, Warsaw PL-02-668, Poland
}

Received 17 August 2005; revised 8 September 2005; accepted 8 September 2005

Available online 25 October 2005

\begin{abstract}
The vibrational spectra of monomeric diazines (pyrazine, pyrimidine and pyridazine) isolated in solid argon and of the neat crystalline phase of these compounds, at $10 \mathrm{~K}$, are reported and discussed. Full assignment of the spectra is presented, providing evidence that the assignments of several bands previously undertaken for the compounds under other experimental conditions (e.g., gas phase, neat liquid or solution) shall be reconsidered. The interpretation of the experimental data is supported by extensive DFT calculations performed with the B3LYP functional and the 6-311+ + G(d,p) basis set and by comparison with the anharmonic vibrational calculations reported by Boese and Martin [J.Phys.Chem. A, 108 (2004) 3085] and Berezin et al. [Russian J.Phys.Chem., 79 (2005) 425; Opt.Spectrosc., 97 (2004) 201]. Spectra/structure correlations were extracted from the data, enabling to conclude that, while the $\pi$-electron systems in both pyrazine and pyrimidine rings are strongly delocalized over all heavy-atoms, in pyridazine the canonical form with one CC and two CN double bonds strongly predominates. Finally, the UV-induced photoisomerization of matrix isolated monomeric pyrazine to pyrimidine is reported.
\end{abstract}

(C) 2005 Elsevier B.V. All rights reserved.

Keywords: Pyridazine; Pyrimidine; Pyrazine; Matrix isolation; IR spectroscopy; Photolysis

\section{Introduction}

The diazine rings are building blocks of many important natural and synthetic compounds, e.g., nucleotides. This is why, the simplest diazines: pyrazine, pyrimidine and pyridazine (Fig. 1), have early attracted attention of chemists.

The infrared (IR) spectra collected, in the $2000-750 \mathrm{~cm}^{-1}$ range, for the compounds at room temperature, were first reported in the book by Barnes et al., in 1944 [1]. Later on, the IR spectrum of pyrimidine was discussed briefly by Brownlie [2] and by Short and Thompson [3]. Other early studies of diazines concerned an electron diffraction on pyrazine [4] and UV spectroscopy of all three diazines [5-8]. The first systematic comparative studies on the vibrational spectroscopy of the three compounds were reported, in 1956, by Ito et al. [9] and Lord, Marston and Miller [10], who investigated the compounds in their neat liquid phases and in solutions in different solvents (for pyrazine, also in the vapor phase). In these studies, the band assignments were made by analogy with

\footnotetext{
* Corresponding author. Tel.: +351 23985 2080; fax: +35123982 7703

E-mail address: rfausto@ci.uc.pt (R. Fausto).
}

0022-2860/\$ - see front matter (C) 2005 Elsevier B.V. All rights reserved. doi:10.1016/j.molstruc.2005.09.010 the corresponding frequencies of benzene, pyridine and their various deuterated derivates.

\subsection{Pyridazine}

At that time, relatively little further structural information was available for pyridazine; even the crystal structure was not known. On the basis of the assignments of Lord, Marston and Miller [10], V.Berezin [11] developed an empirical GVFF-type force field, which, however, was not always in accordance with the results presented by the first authors. Later, Stidham and Tucci (1967) [12], synthesized four isotopically substituted pyridazines of identical $\left(\mathrm{C}_{2 \mathrm{v}}\right)$ symmetry and reported their IR spectra in the $4000-270 \mathrm{~cm}^{-1}$ range. The proposed vibrational assignments were claimed to satisfy the three Teller-Redlich product rules within limitations imposed by evident Fermi resonance perturbation of some of the fundamentals [12]. However, several changes to the assignments made by Stidham and Tucci [12] were later proposed by Jordan and Parmenter [13], Chappel and Ross [14], Ozono et al., [15] Wiberg [16,17], Navarro et al. [18] and Bérces et al., [19] some of these supported by results of empirically-based traditional normal mode analysis or low-level ab initio predictions of the vibrational spectra. Higher level theoretical calculations of vibrational spectra of pyridazine (undertaken still within the harmonic approximation) were reported more recently by 

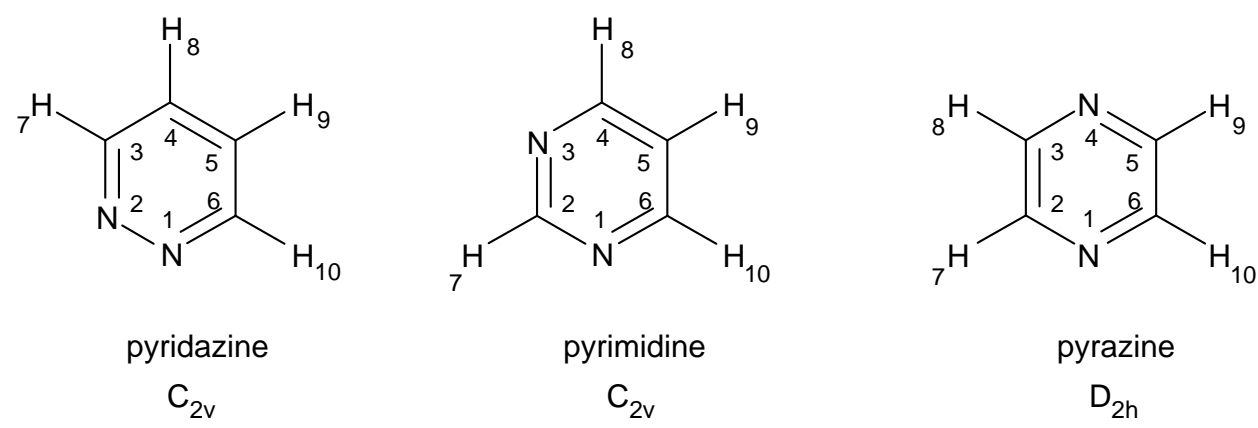

Fig. 1. Atom numbering of diazines.

Billes et al. [20,21] and Martin and Alsenoy [22], whereas Boese and Martin [23] and K. Berezin, Nechaev and El'kin [24] reviewed the vibrational assignments for pyridazine taking into consideration results of anharmonic vibrational calculations. In the latter study, performed at the DFT(B3LYP)/6$31 \mathrm{G}(\mathrm{d})$ level of theory, both Fermi and Darling-Dennison resonances were taken into account, and their spectral manifestations analyzed. Some of the abovementioned studies dealt also with pyrimidine and/or pyrazine. [14,16,20-23]

The molecular structure of pyridazine was first determined from electron-diffraction and microwave data collected for the compound in the gas phase as well as from direct dipolar coupling in the H-NMR spectrum recorded (by Cradock et al., [25] in 1990) for pyridazine in a liquid-crystal solvent. The combination of applied techniques allowed to fully resolve the structure of the compound without any a priori assumption. In the following year, Blacke and Rankin [26] determined the complete crystal structure of pyridazine, at $100 \mathrm{~K}$, by X-ray diffraction. These authors found the bond angles within the pyridazine molecule in the crystalline state to be similar to those observed for free molecules of the compound in the gas phase. However, there were significant differences in bond lengths, which were ascribed to crystal packing effects [26]. On the basis of the observed shortening of the $\mathrm{C}-\mathrm{N}$ bonds and the $\mathrm{C}-\mathrm{C}$ bond opposite to the $\mathrm{N}-\mathrm{N}$ bond, Blacke and Rankin suggested that a free molecule of pyridazine should be more aromatic than molecules in the solid crystalline phase [26].

\subsection{Pyrimidine}

The number of studies on the vibrational spectroscopy of pyrimidine reported after publication of the keystone papers by Ito et al. [9] and Lord, Marston and Miller [10] is considerably large. These reports describe investigations of the compound in the vapor phase [21], in the neat condensed phases and in solutions [27-30], as well as the results of theoretical predictions (including anharmonic calculations) [31,32]. Also pyrimidine isolated in cryogenic argon matrices was investigated by Destexhe et al. [33] and McCarthy et al. [34,35] In these studies monomers and dimers of pyrimidine, as well as pyrimidine-water complexes were investigated by a combined application of matrix isolation IR spectroscopy and ab initio calculations. Besides the general assignment of the spectra of monomeric pyrimidine, spectroscopic features originated in the aggregates could also be identified in the experimental spectra. On the basis of theoretical calculations [34], a structure was proposed for the most stable pyrimidine dimer.

The molecular structure of pyrimidine in the gas-phase was investigated by electron diffraction (by Fernholt and Römming [36]) and by rotational spectroscopy (by Kisiel et al., [37]). The crystal structure of the compound was solved much earlier (1960), by Wheatley [38]. In the gaseous phase, the molecule was found to have the $\mathrm{CN}$ bond lengths equal within the experimental error (134.0 pm) [36,37] and the CC bond lengths $(139.3 \mathrm{pm})$ similar to those found in benzene. The internal ring angles for the isolated molecule were found to be identical to those observed in the crystalline state. On the whole the available structural results point to a considerable aromatic character of the molecule [36-38].

\subsection{Pyrazine}

Contrarily to the other two diazines, the molecular structure of pyrazine was determined long ago, both by gas-phase electron diffraction [39] and by X-ray analysis [40]. In 1977, Bormans, With and Mijlhoff [41], reinvestigated the molecular structure of this compound by electron diffraction and compared the obtained $\mathrm{r}_{\mathrm{g}}$-type structure of pyrazine with those of benzene and pyridine. They noted that both the $\mathrm{CN}$ and $\mathrm{CC}$ bond lengths are equal in pyrazine and pyridine within limits of the experimental error, whereas the latter seem to be slightly longer in these molecules than in benzene. In addition, in both pyrazine and pyridine the $\mathrm{CNC}$ and $\mathrm{NCH}$ angles were found to be smaller and the NCC angles larger than $120^{\circ}$ by a few degrees.

The vibrational spectra of pyrazine and some of its isotopologues, in both vapor and crystalline phases, were first studied in detail by Califano, Adembri and Sbrana [42], in 1964. The vibrational assignment of the spectra of various isotopic species was discussed on the basis of the rotational envelopes, polarization measurements and taking into account the Teller-Redlich product rules. All infrared active modes were successfully assigned, and from the infrared spectrum of cis pyrazine- $\mathrm{d}_{2}$ evidence was also obtained for the assignment of infrared inactive modes of pyrazine. Other experimental or/ and theoretical studies on the vibrational spectra of pyrazine have been reported since then [14,16,20-23,29,43-46]. Among them, the anharmonic vibrational calculations of 
Boese and Martin [23], and the experimental studies of Billes, Mikosch and Holly [21], Arenas et al., [45] Innes, Roos and Moomaw [29] and Kearley et al. [46] are of special importance.

In spite of the extensive list of studies already undertaken on the three diazines, the infrared spectra of pyridazine and pyrazine monomers isolated in inert cryogenic Ar matrices are presented in the current work for the first time. As mentioned above, the infrared spectrum of matrix isolated pyrimidine monomer was studied previously by Destexhe et al. [33] and by McCarthy et al., $[34,35]$ but it is also considered in the present study for comparison. In addition to the matrix isolation data, the spectra of the low temperature crystalline phases of the three compounds were also recorded and interpreted. Finally, the photochemistry of these compounds under matrix-isolation conditions was investigated. In the present work we report generation of pyrimidine upon UV irradiation of matrix-isolated pyrazine.

\section{Experimental and computational details}

The experimental matrix-isolation set-up used in the present study has already been described in detail elsewhere [47]. The compound to be studied was placed in a glass tube protected against light and connected to the chamber of the cryostat by a needle valve. In each experiment, before cooling down the cryostat, the compound was degassed by the standard freezepump-thaw procedure and, subsequently, the vapors over the compound in the tube were evacuated several times at room temperature. This approach enabled removal of possible volatile impurities, allowing an additional purification of the compound, immediately before experiment. In order to deposit a matrix, the vapor of the compound was introduced into the cryostat chamber through the needle valve together with large excess of the host matrix gas (argon N60 from Air Liquide) coming from a separate line. The guest-to-host ratio in matrices was changed in the different experiments in order to guarantee that there were no aggregates in the matrix samples used for subsequent data analysis. The solid amorphous layer was prepared in the same manner as the matrices, but with the flux of the matrix gas stopped.

The infrared spectra were recorded with $0.5 \mathrm{~cm}^{-1}$ resolution using either a Mattson (60AR Infinity Series) or a Thermo Nicolet Nexus 670 FTIR spectrometer equipped with $\mathrm{KBr}$ beam splitter and DTGS detector. Integral intensities of the IR absorption bands were measured by numerical integration.

Matrices were irradiated with the light from a HBO 200 high pressure mercury lamp fitted with the UG11 cutoff filter, or from the pulsed excimer laser (LPX 100 Lambda Physik) operating at $308 \mathrm{~nm}(\mathrm{XeCl})$, with repetition rate $10 \mathrm{~Hz}$, pulse duration $10 \mathrm{~ns}$ and pulse energy $75 \mathrm{~mJ}$.

The equilibrium geometries for all studied molecules were fully optimized at the DFT level of theory with the standard $6-311++\mathrm{G}(\mathrm{d}, \mathrm{p})$ basis set. The DFT calculations were carried out with the three-parameter B3LYP density functional, which includes Becke's gradient exchange correction [48] and the Lee, Yang, Parr correlation functional [49].

The nature of the obtained stationary points on the potential energy surfaces of the respective systems was checked through
Table 1

Symmetry coordinates used in the normal mode analysis for the pyridazine (atom numbering as in Fig. 1)
$\mathbf{A}_{1}$

$\mathrm{S}_{1}=r_{1,2}$

$\mathrm{S}_{2}=\left(2^{-1 / 2}\right)\left(r_{2,3}+r_{6,1}\right)$

$\mathrm{S}_{3}=r_{4,5}$

$\mathrm{S}_{4}=\left(2^{-1 / 2}\right)\left(r_{3,4}+r_{5,6}\right)$

$\mathrm{S}_{5}=(1 / 2)\left(r_{3,7}+r_{4,8}+r_{5,9}+r_{6,10}\right)$

$\mathrm{S}_{6}=(1 / 2)\left(r_{3,7}-r_{4,8}-r_{5,9}+r_{6,10}\right)$

$\mathrm{S}_{7}=\left(12^{-1 / 2}\right)\left(2 \beta_{2,4,3}-\beta_{3,5,4}-\beta_{4,6,5}+2 \beta_{5,1,6}-\beta_{6,2,1}-\beta_{1,3,2}\right)$

$\mathrm{S}_{8}=\left(8^{-1 / 2}\right)\left(\beta_{7,2,3}-\beta_{7,4,3}+\beta_{8,3,4}-\beta_{8,5,4}-\beta_{9,4,5}+\beta_{9,6,5}-\right.$ $-\beta_{10,5,6}+\beta_{10,1,6}$

$\mathrm{S}_{9}=\left(8^{-1 / 2}\right)\left(\beta_{7,2,3}-\beta_{7,4,3}-\beta_{8,3,4}+\beta_{8,5,4}+\beta_{9,4,5}-\beta_{9,6,5}-\right.$ $\left.-\beta_{10,5,6}+\beta_{10,1,6}\right)$

$\mathbf{B}_{2}$

$\mathrm{S}_{10}=\left(2^{-1 / 2}\right)\left(r_{2,3}-r_{6,1}\right)$

$\mathrm{S}_{11}=\left(2^{-1 / 2}\right)\left(r_{3,4}-r_{5,6}\right)$

$\mathrm{S}_{12}=(1 / 2)\left(r_{3,7}+r_{4,8}-r_{5,9}-r_{6,10}\right)$

$\mathrm{S}_{13}=(1 / 2)\left(r_{3,7}-r_{4,8}+r_{5,9}-r_{6,10}\right)$

$S_{14}=\left(6^{-1 / 2}\right)\left(\beta_{2,4,3}-\beta_{3,5,4}+\beta_{4,6,5}-\beta_{5,1,6}+\beta_{6,2,1}-\beta_{1,3,2}\right)$

$\mathrm{S}_{15}=(1 / 2)\left(\beta_{3,5,4}-\beta_{4,6,5}+\beta_{6,2,1}-\beta_{1,3,2}\right)$

$\mathrm{S}_{16}=\left(8^{-1 / 2}\right)\left(\beta_{7,2,3}-\beta_{7,4,3}+\beta_{8,3,4}-\beta_{8,5,4}+\beta_{9,4,5}-\beta_{9,6,5}+\right.$ $\left.+\beta_{10,5,6}-\beta_{10,1,6}\right)$

$\mathrm{S}_{17}=\left(8^{-1 / 2}\right)\left(\beta_{7,2,3}-\beta_{7,4,3}-\beta_{8,3,4}+\beta_{8,5,4}-\beta_{9,4,5}+\beta_{9,6,5}+\right.$ $\left.+\beta_{10,5,6}-\beta_{10,1,6}\right)$

$\mathbf{A}_{2}$

$\mathrm{S}_{18}=\left(6^{-1 / 2}\right)\left(\tau_{6,1,2,3}-\tau_{1,2,4}+\tau_{2,3,45}-\tau_{3,4,5,6}+\tau_{4,5,6,1}-\right.$ $-\tau_{5,6,1,2)}$

$\mathrm{S}_{19}=\left(12^{-1 / 2}\right)\left(2 \tau_{6,1,2,3}-\tau_{1,2,3,4}-\tau_{2,3,4,5}+2 \tau_{3,4,5,6}-\tau_{4,5,6,1}-\right.$ $\left.-\tau_{5,6,1,2}\right)$

$S_{20}=(1 / 2)\left(\gamma_{7,2,3,4}+\gamma_{8,3,4,5}-\gamma_{9,4,5,6}-\gamma_{10,5,6,1}\right)$

$S_{21}=(1 / 2)\left(\gamma_{7,2,3,4}-\gamma_{8,3,4,5}+\gamma_{9,4,5,6}-\gamma_{10,5,6,1}\right)$

$\mathbf{B}_{1}$

$\mathrm{S}_{22}=(1 / 2)\left(\tau_{1,2,3,4}-\tau_{2,3,4,5}+\tau_{4,5,6,1}-\tau_{5,6,1,2}\right)$

$S_{23}=(1 / 2)\left(\gamma_{7,2,3,4}+\gamma_{8,3,4,5}+\gamma_{9,4,5,6}+\gamma_{10,5,6,1}\right)$

$\mathrm{S}_{24}=(1 / 2)\left(\gamma_{7,2,3,4}-\gamma_{8,3,4,5}-\gamma_{9,4,5,6}+\gamma_{10,5,6,1}\right)$

$\nu(\mathrm{NN})$

$\nu(\mathrm{NC})_{\mathrm{s}}$

$\nu(\mathrm{C} 4 \mathrm{C} 5)$

$\nu(\mathrm{CC})_{\mathrm{s}}$

$\nu(\mathrm{CH})_{\mathrm{s}}$

$\nu(\mathrm{CH})_{\mathrm{s}}$

$\delta$ ring 2

$\delta(\mathrm{CH})_{\mathrm{s}}$

$\delta(\mathrm{CH})^{\prime}$ s

$\nu(\mathrm{NC})_{\mathrm{as}}$

$\nu(\mathrm{CC})_{\text {as }}$

$\nu(\mathrm{CH})_{\text {as }}$

$\nu(\mathrm{CH})$ ' as

$\delta$ ring 1

$\delta$ ring 3

$\delta(\mathrm{CH})_{\text {as }}$

$\delta(\mathrm{CH})^{\prime}$ as

$\tau$ ring 1

$\tau$ ring 2

$\gamma(\mathrm{CH})_{\text {as }}$ $\gamma(\mathrm{CH})$ ' as

$\tau$ ring 3

$\gamma(\mathrm{CH})_{\mathrm{s}}$

$\gamma(\mathrm{CH}){ }_{\mathrm{s}}$

$r_{\mathrm{i}, \mathrm{j}}$ is the distance between atoms $\mathrm{A}_{\mathrm{i}}$ and $\mathrm{A}_{\mathrm{j}} ; \beta_{\mathrm{i}, \mathrm{j}, \mathrm{k}}$ is the angle between vectors $A_{k} A_{i}$ and $A_{k} A_{j} ; \tau_{i, j, k, 1}$ is the dihedral angle between the plane defined by $A_{i}, A_{j}$, $A_{k}$ and the plane defined by $A_{j}, A_{k}, A_{1}$ atoms; $\gamma_{i, j, k, 1}$ is the angle between the vector $A_{k} A_{i}$ and the plane defined by atoms $A_{j}, A_{k}, A_{1}$.

the analysis of the corresponding Hessian matrix. For each of the studied compounds, a set of symmetry coordinates was defined and the Cartesian force constants were transformed to the internal coordinate space, allowing ordinary normalcoordinate analysis to be performed as described by Schachtschneider [50]. The calculated harmonic frequencies (scaled by 0.978 ) were used to assist the analysis of the experimental spectra. The sets of symmetry coordinates defined for pyridazine, pyrimidine and pyrazine are given in Tables $1-3$, respectively.

All calculations in this work were done using the Gaussian 98 program [51].

\section{Results and discussion}

\subsection{Pyridazine}

The IR spectra of pyridazine monomer in an argon matrix and of the crystalline phase of the compound at low temperature $(10 \mathrm{~K})$ are shown in Fig. 2, together with 
Table 2

Symmetry coordinates used in the normal mode analysis for the pyrimidine (atom numbering as in Fig. 1)

\section{$\mathbf{A}_{1}$}

$\mathrm{S}_{1}=\left(2^{-1 / 2}\right)\left(r_{1,2}+r_{2,3}\right)$

$\mathrm{S}_{2}=\left(2^{-1 / 2}\right)\left(r_{3,4}+r_{6,1}\right)$

$\mathrm{S}_{3}=\left(2^{-1 / 2}\right)\left(r_{4,5}+r_{5,6}\right)$

$\mathrm{S}_{4}=r_{2,7}$

$\mathrm{S}_{5}=\left(2^{-1 / 2}\right)\left(r_{4,8}+r_{6,10}\right)$

$\mathrm{S}_{6}=r_{5,9}$

$\mathrm{S}_{7}=\left(6^{-1 / 2}\right)\left(\beta_{1,3,2}-\beta_{2,4,3}+\beta_{3,5,4}-\beta_{4,6,5}+\beta_{5,1,6}-\beta_{6,2,1}\right)$

$\mathrm{S}_{8}=\left(12^{-1 / 2}\right)\left(2 \beta_{1,3,2}-\beta_{2,4,3}-\beta_{3,5,4}+2 \beta_{4,6,5}-\beta_{5,1,6}-\beta_{6,2,1}\right)$

$\mathrm{S}_{9}=(1 / 2)\left(\beta_{8,3,4}-\beta_{8,5,4}-\beta_{10,5,6}+\beta_{10,1,6}\right)$

$\mathbf{B}_{2}$

$\mathrm{S}_{10}=\left(2^{-1 / 2}\right)\left(r_{1,2}-r_{2,3}\right)$

$\mathrm{S}_{11}=\left(2^{-1 / 2}\right)\left(r_{3,4}-r_{6,1}\right)$

$\mathrm{S}_{12}=\left(2^{-1 / 2}\right)\left(r_{4,5}-r_{5,6}\right)$

$\mathrm{S}_{13}=\left(2^{-1 / 2}\right)\left(r_{4,8}-r_{6,10}\right)$

$\mathrm{S}_{14}=(1 / 2)\left(\beta_{2,4,3}-\beta_{3,5,4}+\beta_{5,1,6}-\beta_{6,2,1}\right)$

$\mathrm{S}_{15}=\left(2^{-1 / 2}\right)\left(\beta_{7,1,2}-\beta_{7,3,2}\right)$

$\mathrm{S}_{16}=(1 / 2)\left(\beta_{8,3,4}-\beta_{8,5,4}+\beta_{10,5,6}-\beta_{10,1,6}\right)$

$\mathrm{S}_{17}=\left(2^{-1 / 2}\right)\left(\beta_{9,4,5}-\beta_{9,6,5}\right)$

$\mathbf{B}_{1}$

$\mathrm{S}_{18}=\left(6^{-1 / 2}\right)\left(\tau_{6,1,2,3}-\tau_{1,2,3,4}+\tau_{2,3,4,5}-\tau_{3,4,5,6}+\tau_{4,5,6,1}-\tau_{5,6,1,2}\right)$

$\mathrm{S}_{19}=(1 / 2)\left(\tau_{6,1,2,3}-\tau_{1,2,3,4}+\tau_{3,4,5,6}-\tau_{4,5,6,1}\right)$

$\mathrm{S}_{20}=\gamma_{7,1,2,3}$

$\mathrm{S}_{21}=\left(2^{-1 / 2}\right)\left(\gamma_{8,3,4,5}+\gamma_{10,5,6,1}\right)$

$\mathrm{S}_{22}=\gamma_{9,4,5,6}$

$\mathbf{A}_{2}$

$\mathrm{S}_{23}=\left(12^{-1 / 2}\right)\left(-\tau_{6,1,2,3}-\tau_{1,2,3,4}+2 \tau_{2,3,4,5}-\tau_{3,4,5,6}-\tau_{4,5,6,1}+\right.$ $\left.+2 \tau_{5,6,1,2}\right)$

$\mathrm{S}_{24}=\left(2^{-1 / 2}\right)\left(\gamma_{8,3,4,5}-\gamma_{10,5,6,1}\right)$

$\nu(\mathrm{NC})_{\mathrm{s}}^{1}$

$\nu(\mathrm{NC})^{2} \mathrm{~s}$

$\nu(\mathrm{CC})_{\mathrm{s}}$

$\nu(\mathrm{C} 2 \mathrm{H} 7)$

$\nu(\mathrm{CH})_{\mathrm{s}}$

$\nu$ (C5H9)

$\delta$ ring 1

$\delta$ ring 2

$\delta(\mathrm{CH})_{\mathrm{s}}$

$\nu(\mathrm{NC})^{1}$ as

$\nu(\mathrm{NC})^{2}$ as

$\nu(\mathrm{CC})_{\mathrm{as}}$

$\nu(\mathrm{CH})_{\text {as }}$

$\delta$ ring 3

$\delta(\mathrm{C} 2 \mathrm{H} 7)$

$\delta(\mathrm{CH})_{\text {as }}$

$\delta(\mathrm{C} 5 \mathrm{H} 9)$

$\tau$ ring 1

$\tau$ ring 3

$\gamma(\mathrm{C} 2 \mathrm{H} 7)$

$\gamma(\mathrm{CH})_{\mathrm{s}}$

$\gamma(\mathrm{C} 5 \mathrm{H} 9)$

$\tau$ ring 2

$\gamma(\mathrm{CH})_{\mathrm{as}}$

$r_{\mathrm{i}, \mathrm{j}}$ is the distance between atoms $\mathrm{A}_{\mathrm{i}}$ and $\mathrm{A}_{\mathrm{j}} ; \beta_{\mathrm{i}, \mathrm{j}, \mathrm{k}}$ is the angle between vectors $\mathrm{A}_{\mathrm{k}} \mathrm{A}_{\mathrm{i}}$ and $\mathrm{A}_{\mathrm{k}} \mathrm{A}_{\mathrm{j}} ; \tau_{\mathrm{i}, \mathrm{j}, \mathrm{k}, 1}$ is the dihedral angle between the plane defined by $\mathrm{A}_{\mathrm{i}}, \mathrm{A}_{\mathrm{j}}$, $A_{k}$ and the plane defined by $A_{j}, A_{k}, A_{1}$ atoms; $\gamma_{i, j, k, 1}$ is the angle between the vector $A_{k} A_{i}$ and the plane defined by atoms $A_{j}, A_{k}, A_{1}$.

the spectrum calculated for this compound at the DFT(B3LYP)/6-311+ + G(d,p) level. Band assignments and results of normal coordinate analysis are provided in Table 4. Selected literature data [52] for the liquid phase are also presented in this table, for comparison. The notation of the vibrations of pyridazine, used by Boese and Martin [23], has been adopted also in the present work (see Table 4).

The very close match between the calculated data and the experimental spectrum of matrix-isolated pyridazine allows clarification of some band assignments that have been contradictory or equivocal in the literature. For instance, the controversy concerning the assignment of either the band at ca. $1570 \mathrm{~cm}^{-1}[12,21,53]$ or the band at ca. $1550 \mathrm{~cm}^{-1}[15,18,23]$ to mode (3) (with $A_{1}$ symmetry), could be solved in favor of the band at higher frequency. Indeed, in the spectrum of the matrix-isolated compound, a band (ascribable to mode (3)) was observed at $1572.9 \mathrm{~cm}^{-1}$, whereas the region around $1550 \mathrm{~cm}^{-1}$ is free of any IR absorption (see Fig. 2). This conclusion can also be extracted from the low temperature crystal spectrum, where the band ascribable to mode (3) is observed at $1573.2 \mathrm{~cm}^{-1}$. Mode (4) $\left(\mathrm{A}_{1}\right)$ shall be definitely ascribed to the band at ca. $1440 \mathrm{~cm}^{-1}$ (in the argon matrix: $1441.3 \mathrm{~cm}^{-1}$ ), as previously proposed by Ozono et al. [15], Vazquez et al. [53] and Boese and Martin [23], while the band
Table 3

Symmetry coordinates used in the normal mode analysis for the pyrazine (atom numbering as in Fig. 1)

$\mathbf{A}_{\mathrm{g}}$

$\mathrm{S}_{1}=(1 / 2)\left(r_{1,2}+r_{3,4}+r_{4,5}+r_{6,1}\right) \quad \nu(\mathrm{NC})$

$\mathrm{S}_{2}=\left(2^{-1 / 2}\right)\left(r_{2,3}+r_{5,6}\right)$

$\mathrm{S}_{3}=(1 / 2)\left(r_{2,7}+r_{3,8}+r_{5,9}+r_{6,10}\right)$

阮, $\left.-\beta_{2,4,3}+2 \beta_{3,5,4}-\beta_{4,6,5}-\beta_{5,1,6}+2 \beta_{6,2,1}\right) \quad \delta$ ring 2

$\mathrm{S}_{5}=\left(8^{-1 / 2}\right)\left(\beta_{7,1,2}-\beta_{7,3,2}-\beta_{8,2,3}+\beta_{8,4,3}+\beta_{9,4,5}-\beta_{9,6,5}-\quad \delta(\mathrm{CH})_{\mathrm{s}}\right.$

$$
\left.-\beta_{10,5,6}+\beta_{10,1,6}\right)
$$

$\mathbf{B}_{3 \mathrm{~g}}$

$\mathrm{S}_{6}=(1 / 2)\left(r_{1,2}-r_{3,4}+\mathrm{r}_{4,5}-r_{6,1}\right)$

$\mathrm{S}_{7}=(1 / 2)\left(r_{2,7}-r_{3,8}+r_{5,9}-r_{6,10}\right)$

$\mathrm{S}_{8}=(1 / 2)\left(\beta_{1,3,2}-\beta_{2,4,3}+\beta_{4,6,5}-\beta_{5,1,6}\right)$

$\mathrm{S}_{9}=\left(8^{-1 / 2}\right)\left(\beta_{7,1,2}-\beta_{7,3,2}+\beta_{8,2,3}-\beta_{8,4,3}+\beta_{9,4,5}-\beta_{9,6,5}+\right.$ $\left.+\beta_{10,5,6}-\beta_{10,1,6}\right)$

$\mathbf{B}_{1 \mathbf{u}}$

$\mathrm{S}_{10}=(1 / 2)\left(r_{1,2}-r_{3,4}-r_{4,5}+r_{6,1}\right)$

$\mathrm{S}_{11}=(1 / 2)\left(r_{2,7}-r_{3,8}-r_{5,9}+r_{6,10}\right)$

$\mathrm{S}_{12}=\left(6^{-1 / 2}\right)\left(\beta_{1,3,2}-\beta_{2,4,3}+\beta_{3,5,4}-\beta_{4,6,5}+\beta_{5,1,6}-\beta_{6,2,1}\right)$

$\mathrm{S}_{13}=\left(8^{-1 / 2}\right)\left(\beta_{7,1,2}-\beta_{7,3,2}+\beta_{8,2,3}-\beta_{8,4,3}-\beta_{9,4,5}+\beta_{9,6,5}-\right.$ $\left.-\beta_{10,5,6}+\beta_{10,1,6}\right)$

$\mathbf{B}_{\mathbf{2 u}}$

$\mathrm{S}_{14}=(1 / 2)\left(r_{1,2}+r_{3,4}-r_{4,5}-r_{6,1}\right)$

$\mathrm{S}_{15}=(1 / 2)\left(r_{2,7}+r_{3,8}-r_{5,9}-r_{6,10}\right)$

$\mathrm{S}_{16}=\left(2^{-1 / 2}\right)\left(r_{2,3}-r_{5,6}\right)$

$\mathrm{S}_{17}=\left(8^{-1 / 2}\right)\left(\beta_{7,1,2}-\beta_{7,3,2}-\beta_{8,2,3}+\beta_{8,4,3}-\beta_{9,4,5}+\beta_{9,6,5}+\right.$ $\left.+\beta_{10,5,6}-\beta_{10,1,6}\right)$

$\nu(\mathrm{NC})_{\text {as }}$ $\nu(\mathrm{CH})_{\text {as }}$ $\delta$ ring 3 $\delta(\mathrm{CH})_{\text {as }}$

$\mathbf{B}_{1 \mathrm{~g}}$

$\mathrm{S}_{18}=(1 / 2)\left(\gamma_{7,1,2,3}+\gamma_{8,2,3,4}-\gamma_{9,4,5,6}-\gamma_{10,5,6,1}\right)$

$\nu(\mathrm{NC})^{\prime}$ as $\nu(\mathrm{CH})^{\prime}$ as $\delta$ ring 1 $\delta(\mathrm{CH})^{\prime}$ as

$\mathbf{B}_{2 \mathbf{g}}$

$\mathrm{S}_{19}=\left(6^{-1 / 2}\right)\left(\tau_{6,1,2,3}-\tau_{1,2,3,4}+\tau_{2,3,4,5}-\tau_{3,4,5,6}+\tau_{4,5,6,1}-\tau_{5,6,1,2}\right)$

$\mathrm{S}_{20}=(1 / 2)\left(\gamma_{7,1,2,3}-\gamma_{8,2,3,4}-\gamma_{9,4,5,6}+\gamma_{10,5,6,1}\right)$

$\mathbf{A}_{\mathbf{u}}$ $\begin{aligned} \mathrm{S}_{21}= & \left(12^{-1 / 2}\right)\left(-\tau_{6,1,2,3}+2 \tau_{1,2,3,4}-\tau_{2,3,4,5}-\tau_{3,4,5,6}+2 \tau_{4,5,6,1}-\quad \tau \text { ring } 2\right. \\ & \left.-\tau_{5,6,1,2}\right)\end{aligned}$

$\mathrm{S}_{22}=(1 / 2)\left(\gamma_{7,1,2,3}-\gamma_{8,2,3,4}+\gamma_{9,4,5,6}-\gamma_{10,5,6,1}\right)$

$\gamma(\mathrm{CH})_{\text {as }}$

$\mathbf{B}_{\mathbf{3 u}}$

$\mathrm{S}_{23}=(1 / 2)\left(\tau_{2,3,4,5}-\tau_{3,4,5,6}+\tau_{5,6,1,2}-\tau_{6,1,2,3}\right)$

$\tau$ ring 3

$\mathrm{S}_{24}=(1 / 2)\left(\gamma_{7,1,2,3}+\gamma_{8,2,3,4}+\gamma_{9,4,5,6}+\gamma_{10,5,6,1}\right)$ $\gamma(\mathrm{CH})_{\mathrm{s}}$

$r_{\mathrm{i}, \mathrm{j}}$ is the distance between atoms $\mathrm{A}_{\mathrm{i}}$ and $\mathrm{A}_{\mathrm{j}} ; \beta_{\mathrm{i}, \mathrm{j}, \mathrm{k}}$ is the angle between vectors $\mathrm{A}_{k} \mathrm{~A}_{\mathrm{i}}$ and $\mathrm{A}_{k} \mathrm{~A}_{\mathrm{j}} ; \tau_{\mathrm{i}, \mathrm{j}, \mathrm{k}, 1}$ is the dihedral angle between the plane defined by $\mathrm{A}_{\mathrm{i}}, \mathrm{A}_{\mathrm{j}}$, $A_{k}$ and the plane defined by $A_{j}, A_{k}, A_{1}$ atoms; $\gamma_{i, j, k, 1}$ is the angle between the vector $A_{k} A_{i}$ and the plane defined by atoms $A_{j}, A_{k}, A_{l}$.

at ca. $1415 \mathrm{~cm}^{-1}\left(1412.4 \mathrm{~cm}^{-1}\right.$ in $\operatorname{argon}$ matrix $)$, which has also been proposed by some authors $[12,21]$ as originated in this mode, could now be safely assigned to mode (17), of $\mathrm{B}_{2}$ symmetry. The assignment of mode $(5)\left(\mathrm{A}_{1}\right)$ has been the subject of much controversy, being most of times wrongly assigned to the band with frequency around $1345 \mathrm{~cm}^{-1}$ [12,15,21]. As already suggested by Boese and Martin [23], this mode shall in fact give rise to a band at a considerably lower frequency. In consonance with the theoretical simulations (including the anharmonic calculations presented in Ref. [23]), which predict mode (5) with frequency around $1157 \mathrm{~cm}^{-1}$, a very weak band at ca. $1159 \mathrm{~cm}^{-1}$ was observed in the spectra of more concentrated matrices of pyridazine. The intensity of this band grows considerably with increasing aggregation of pyridazine in matrices. This band has a 

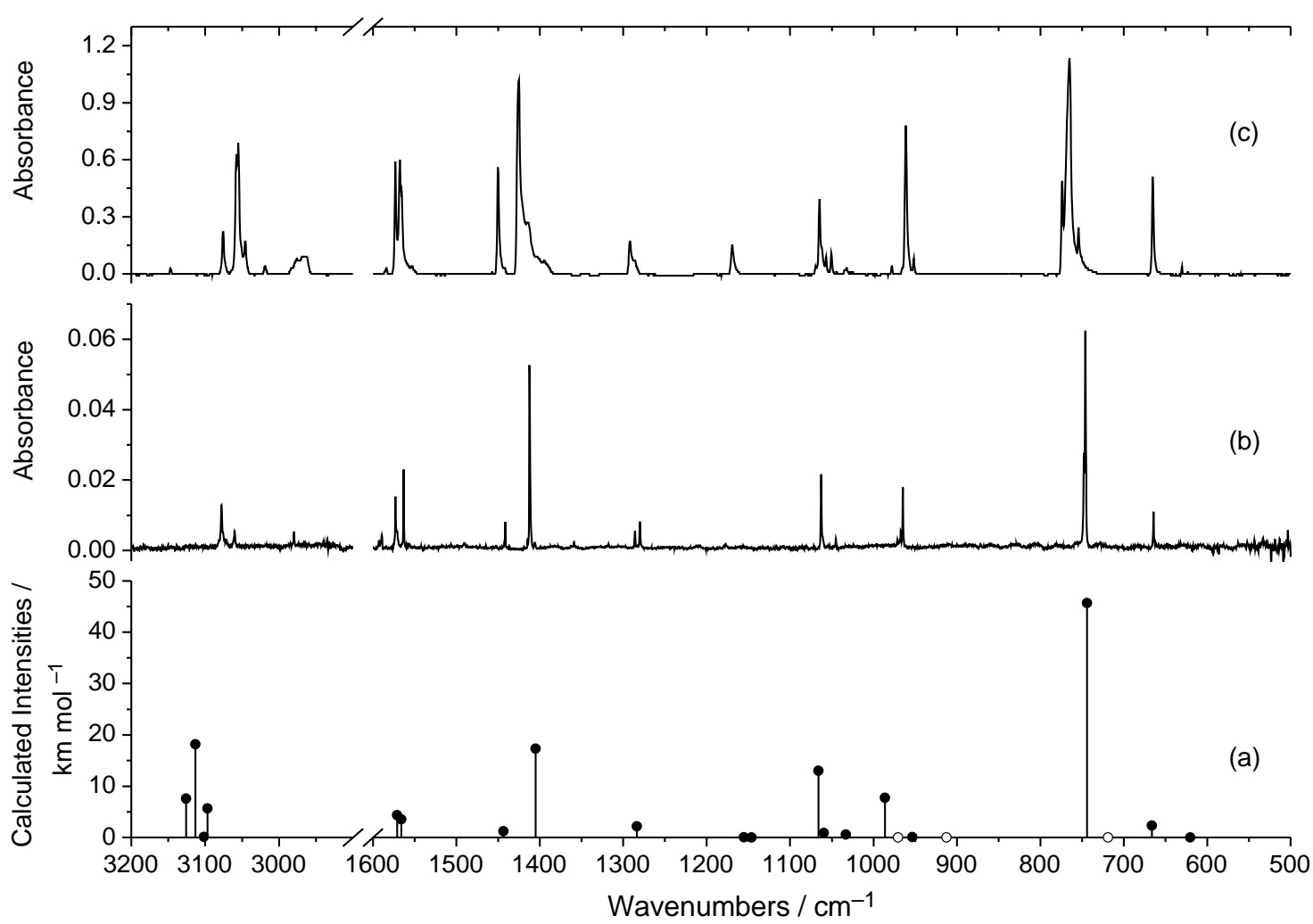

Fig. 2. Calculated infrared spectrum of pyridazine monomer (a) and observed infrared spectra of pyridazine isolated in an argon matrix at $10 \mathrm{~K}$ (b) and in the low temperature crystalline phase (c). In the calculated spectrum, open circles indicate the positions of the IR inactive modes. Calculated frequencies are scaled by a single factor 0.978 .

counterpart, in the low temperature crystal spectrum, at $1168.8 \mathrm{~cm}^{-1}$, that shall also be assigned to this vibration. The infrared band corresponding to mode (6) must be very weak (the theoretically predicted intensity is only $0.005 \mathrm{~km} \mathrm{~mol}^{-1}$; see Table 4) and could not be observed.

The assignments for the region below $1050 \mathrm{~cm}^{-1}$ have also been the motive of some controversy in the past. In consonance with the predictions of Boese and Martin [23], and also with our theoretical calculations, the bands corresponding to modes (19) and (20), of $B_{2}$ symmetry, were observed as low-intensity absorptions at 1062.7 and $1045.5 \mathrm{~cm}^{-1}$, respectively. Note that mode (19) has been repeatedly misassigned in the past to the band due to mode (5), around $1168 \mathrm{~cm}^{-1}$ (as discussed above, mode (5) has been wrongly assigned to a band around $1350 \mathrm{~cm}^{-1}$, which is due to a combination tone-see Table 4). Mode (8) $\left(\mathrm{A}_{1}\right)$ shall have frequency in the 990 $965 \mathrm{~cm}^{-1}$ range. In the spectra of pyridazine isolated in argon matrices, the band assigned to this mode appears as a doublet at $967.3 / 964.9 \mathrm{~cm}^{-1}$, corresponding to the band found at $961.4 \mathrm{~cm}^{-1}$ in the spectrum of low-temperature crystalline pyridazine. In turn, the band due to mode $(22)\left(B_{1}\right)$ could not be observed in the matrix spectrum (the predicted intensity for this mode is only $0.09 \mathrm{~km} \mathrm{~mol}^{-1}$; see Table 4), but is observed at $952.2 \mathrm{~cm}^{-1}$, in the spectrum of the low temperature crystal. On the other hand, the $A_{2}$ mode (11) (which for monomeric pyridazine is infrared inactive by symmetry reasons) shall be assigned to the low intensity band at $937.0 \mathrm{~cm}^{-1}$ appearing in the spectrum of the low temperature crystal $\left(938 \mathrm{~cm}^{-1}\right.$ in the liquid phase spectrum [52]). No band could be assigned to the $A_{2}$ mode (10) in the spectrum of the low temperature crystal, and the previously attempted assignment of this mode to the band at $989 \mathrm{~cm}^{-1}$ in the spectrum of the liquid seems to be equivocal, taking into account the calculated value of $970.4 \mathrm{~cm}^{-1}$ (see Table 4). However, the anharmonic calculations of Boese and Martin [23] as well as those of K. Berezin, Nechaev and El'kin [24] predicted this mode at a higher frequency (around $1000 \mathrm{~cm}^{-1}$; note that this is the only mode where a noticeable disagreement was observed between the results of the anharmonic calculations [23,24] and the scaled harmonic frequencies presented in the current study). Thus, assuming correctness of the frequencies calculated using anharmonic approach, the assignment of the $989 \mathrm{~cm}^{-1}$ band observed in liquid phase to mode (10) could be possible. Raman data for the matrix-isolated compound seems to be the best way to solve this question, but such experiment is currently beyond our experimental facilities. The assignment of modes (23) and (12) (of $\mathrm{B}_{1}$ and $\mathrm{A}_{2}$ symmetry, respectively) is in line with the previous studies and seems unambiguous. On the other hand, observation of the band due to the $A_{1}$ mode (9), in the spectrum of the matrix-isolated compound at $664.3 \mathrm{~cm}^{-1}$ confirms the assignment of Vazquez et al. [53] as well as the assignment suggested by Boese and Martin [23].

On the whole, it can be stated that the present investigation considerably improves the certainty of the assignments of the bands in the vibrational spectra of pyridazine, most of times confirming the expectations raised by the work of Boese and 
Table 4

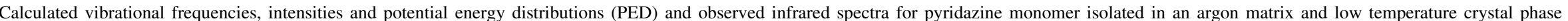
(frequencies $(\nu)$ in $\mathrm{cm}^{-1}$, theoretical intensities $(I)$ in $\mathrm{km} \mathrm{mol}^{-1}$ )

\begin{tabular}{|c|c|c|c|c|c|c|c|c|c|}
\hline \multirow[t]{2}{*}{ Mode $^{\mathrm{a}}$} & \multirow[t]{2}{*}{ Sym. } & \multicolumn{2}{|c|}{$\begin{array}{l}\text { Calculated [B3LYP/6- } \\
311++\mathrm{G}(\mathrm{d}, \mathrm{p})]\end{array}$} & \multirow[t]{2}{*}{$\operatorname{PED}^{\mathrm{c}}(\%)$} & \multicolumn{2}{|c|}{$\begin{array}{c}\text { Monomer } \\
\text { (infrared, Ar matrix, } T=10 \mathrm{~K} \text { ) }\end{array}$} & \multicolumn{2}{|c|}{ Crystal $(T=10 \mathrm{~K})$} & \multirow{2}{*}{$\begin{array}{l}\text { Liquid }^{\mathrm{e}} \\
\frac{[52]}{\nu}\end{array}$} \\
\hline & & $\nu^{\mathrm{b}}$ & $I$ & & $\nu$ & $I^{\mathrm{d}}$ & $\nu$ & $I^{\mathrm{d}}$ & \\
\hline $2 x(3)$ & & & & & & & 3147.0 & 0.8 & \\
\hline (1) & $\mathrm{A}_{1}$ & 3125.6 & 7.6 & $\nu(\mathrm{CH})_{\mathrm{s}}(79.5)+\nu(\mathrm{CH})_{\mathrm{s}}(19.6)$ & 3081.4 & 0.1 & 3075.6 & 2.2 & 3085 \\
\hline (14) & $\mathrm{B}_{2}$ & 3113.2 & 18.2 & $\nu(\mathrm{CH})_{\mathrm{as}}(97.0)$ & 3077.9 & 15.1 & 3057.1 & 14.5 & 3068 \\
\hline (2) & $\mathrm{A}_{1}$ & 3101.8 & 0.1 & $\nu(\mathrm{CH})_{\mathrm{s}}(80.0)+\nu(\mathrm{CH})_{\mathrm{s}}(19.7)$ & & & 3054.5 & & 3056 \\
\hline (15) & $\mathrm{B}_{2}$ & 3096.7 & 5.7 & $\nu(\mathrm{CH})^{\prime}{ }_{\mathrm{as}}(97.3)$ & 3060.2 & 3.5 & 3045.2 & & 3056 \\
\hline$(3)+(4)$ & & & & & & & 3018.8 & 0.8 & \\
\hline$(3)+(17)$ & & & & & 2979.7 & 1.8 & 2975.2 & 5.7 & \\
\hline$(16)+(4)$ & & & & & & & 2966.0 & & \\
\hline$(8)+(21)$ & & & & & & & 1583.8 & 0.5 & \\
\hline (3) & $\mathrm{A}_{1}$ & 1571.0 & 4.3 & $\nu(\mathrm{C} 4 \mathrm{C} 5)(46.8)+\delta(\mathrm{CH})_{\mathrm{s}}(18.9)$ & 1572.9 & 10.3 & 1573.2 & 14.2 & 1570 \\
\hline (16) & $\mathrm{B}_{2}$ & 1566.0 & 3.5 & $\nu(\mathrm{CC})_{\mathrm{as}}(44.3)+\delta(\mathrm{CH})^{\prime}{ }_{\mathrm{as}}(24.4)+\nu(\mathrm{NC})_{\mathrm{as}}(22.7)$ & 1563.3 & 7.8 & 1566.6 & & 1563 \\
\hline (4) & $\mathrm{A}_{1}$ & 1443.6 & 1.2 & $\delta(\mathrm{CH})_{\mathrm{s}}(39.2)+\delta(\mathrm{CH})_{\mathrm{s}}{ }_{\mathrm{s}}(24.0)+\nu(\mathrm{CC})_{\mathrm{s}}(19.3)+\nu(\mathrm{NN})(13.7)$ & 1441.3 & 2.2 & $1457.1 / 1450.3 / 1442.5$ & 5.7 & 1445 \\
\hline (17) & $\mathrm{B}_{2}$ & 1404.9 & 17.3 & $\delta(\mathrm{CH})_{\mathrm{as}}(62.3)+\nu(\mathrm{NC})_{\mathrm{as}}(23.5)$ & 1412.4 & 21.3 & $1425.2 / 1413.3 / 1393.5$ & 28.5 & 1413 \\
\hline$(10)+(11)$ & & & & & 1405.6 & 0.6 & & & \\
\hline$(22)+(13)$ & & & & & 1358.6 & 0.6 & & & \\
\hline$(11)+(24)$ & & & & & 1317.2 & 0.3 & & & \\
\hline FR: (18)/ (9)+(21) & $\mathrm{B}_{2}$ & 1283.7 & 2.2 & $\delta(\mathrm{CH})^{\prime}$ as $(34.9)+\nu(\mathrm{NC})_{\mathrm{as}}(32.7)+\delta(\mathrm{CH})_{\mathrm{as}}(30.5)$ & $1285.9 / 1280.4$ & $1.8 / 2.4$ & $1291.7 / 1285.1$ & 3.5 & 1283 \\
\hline (5) & $A_{1}$ & 1155.3 & 0.05 & $\nu(\mathrm{NC})_{\mathrm{s}}(62.1)+\nu(\mathrm{CC})_{\mathrm{s}}(21.0)+\delta(\mathrm{CH})_{\mathrm{s}}(10.4)$ & $\sim 1159$ & & 1168.8 & 2.2 & 1160 \\
\hline (6) & $\mathrm{A}_{1}$ & 1146.0 & 0.005 & $\delta(\mathrm{CH}){ }_{\mathrm{s}}(59.2)+\delta(\mathrm{CH})_{\mathrm{s}}(16.4)+\nu(\mathrm{NN})(13.6)+\nu(\mathrm{NC})_{\mathrm{s}}(10.5)$ & & & 1136.0 & 1.1 & 1135 \\
\hline (7) & $\mathrm{A}_{1}$ & 1066.0 & 13.0 & $\nu(\mathrm{C} 4 \mathrm{C} 5)(41.0)+\delta(\mathrm{CH})_{\mathrm{s}}(22.6)+\nu(\mathrm{NN})(22.1)+\nu(\mathrm{CC})_{\mathrm{s}}(12.2)$ & 1062.7 & 10.5 & $1064.8 / 1056.7$ & 4.9 & 1074 \\
\hline (19) & $\mathrm{B}_{2}$ & 1059.4 & 0.9 & $\begin{array}{l}\nu(\mathrm{CC})_{\mathrm{as}}(42.3)+\delta(\mathrm{CH})^{\prime}{ }_{\text {as }}(29.5)+\nu(\mathrm{NC})_{\mathrm{as}}(12.7) \\
+\delta \text { ring } 1(10.4)\end{array}$ & 1045.5 & 1.0 & 1050.4 & 0.5 & 1062 \\
\hline (20) & $\mathrm{B}_{2}$ & 1033.2 & 0.5 & $\delta$ ring $1(87.1)$ & 1024.0 & 0.1 & 1032.0 & 0.3 & 1030 \\
\hline$(21)+(13)$ & & & & & 971.4 & 0.5 & 978.0 & 0.5 & 989 \\
\hline (8) & $\mathrm{A}_{1}$ & 986.3 & 7.7 & $\nu(\mathrm{NN})(45.5)+\nu(\mathrm{CC})_{\mathrm{s}}(34.4)+\nu(\mathrm{NC})_{\mathrm{s}}(15.6)$ & $967.3 / 964.9$ & 8.1 & 961.4 & 7.7 & $973 / 965$ \\
\hline (10) & $\mathrm{A}_{2}$ & 970.4 & 0 & $\gamma(\mathrm{CH})^{\prime}{ }_{\text {as }}(105.5)+\gamma(\mathrm{CH})_{\text {as }}(13.5)$ & & & & & \\
\hline (22) & $\mathrm{B}_{1}$ & 953.4 & 0.09 & $\gamma(\mathrm{CH})_{\mathrm{s}}{ }_{\mathrm{s}}(106.4)$ & & & 952.2 & 0.8 & \\
\hline (11) & $\mathrm{A}_{2}$ & 912.4 & 0 & $\gamma(\mathrm{CH})_{\mathrm{as}}(90.7)+\gamma(\mathrm{CH})_{\text {as }}(13.4)$ & & & 937.0 & 0.1 & 938 \\
\hline (23) & $\mathrm{B}_{1}$ & 744.0 & 45.7 & $\gamma(\mathrm{CH})_{\mathrm{s}}(97.0)$ & $747.8 / 745.8$ & 39.0 & $774.7 / 766.1$ & 30.6 & 760 \\
\hline (12) & $\mathrm{A}_{2}$ & 718.7 & 0 & $\tau$ ring $1(114.2)$ & & & 754.6 & & 753 \\
\hline (9) & $\mathrm{A}_{1}$ & 666.3 & 2.3 & $\delta$ ring $2(90.0)$ & 664.3 & 3.5 & 665.5 & 4.1 & 667 \\
\hline (21) & $\mathrm{B}_{2}$ & 620.2 & 0.0005 & $\delta$ ring $3(92.7)$ & & & $630.5 / 623.0$ & $0.3 / 0.1$ & 622 \\
\hline (24) & $\mathrm{B}_{1}$ & 365.6 & 9.3 & $\tau$ ring $3(111.8)$ & & & & & 373 \\
\hline (13) & $\mathrm{A}_{2}$ & 362.2 & 0 & $\tau$ ring $2(106.5)$ & & & & & 369 \\
\hline
\end{tabular}

Liquid phase data extracted from literature is also shown in the table, for comparison.

${ }^{a}$ Numbering of modes follows that used by Boese and Martin [23].

b Theoretical positions of absorption bands were scaled down by a factor of 0.978 .

c PEDs lower than 10\% are not included. Definition of symmetry coordinates is given in Table 1. See Fig. 1 for atom numbering. The theoretical results as symmetry and PEDs are not applicable to the crystal phase.

${ }^{d}$ Relative integrated intensities.

e Includes re-assignments made on the basis of the present results. 


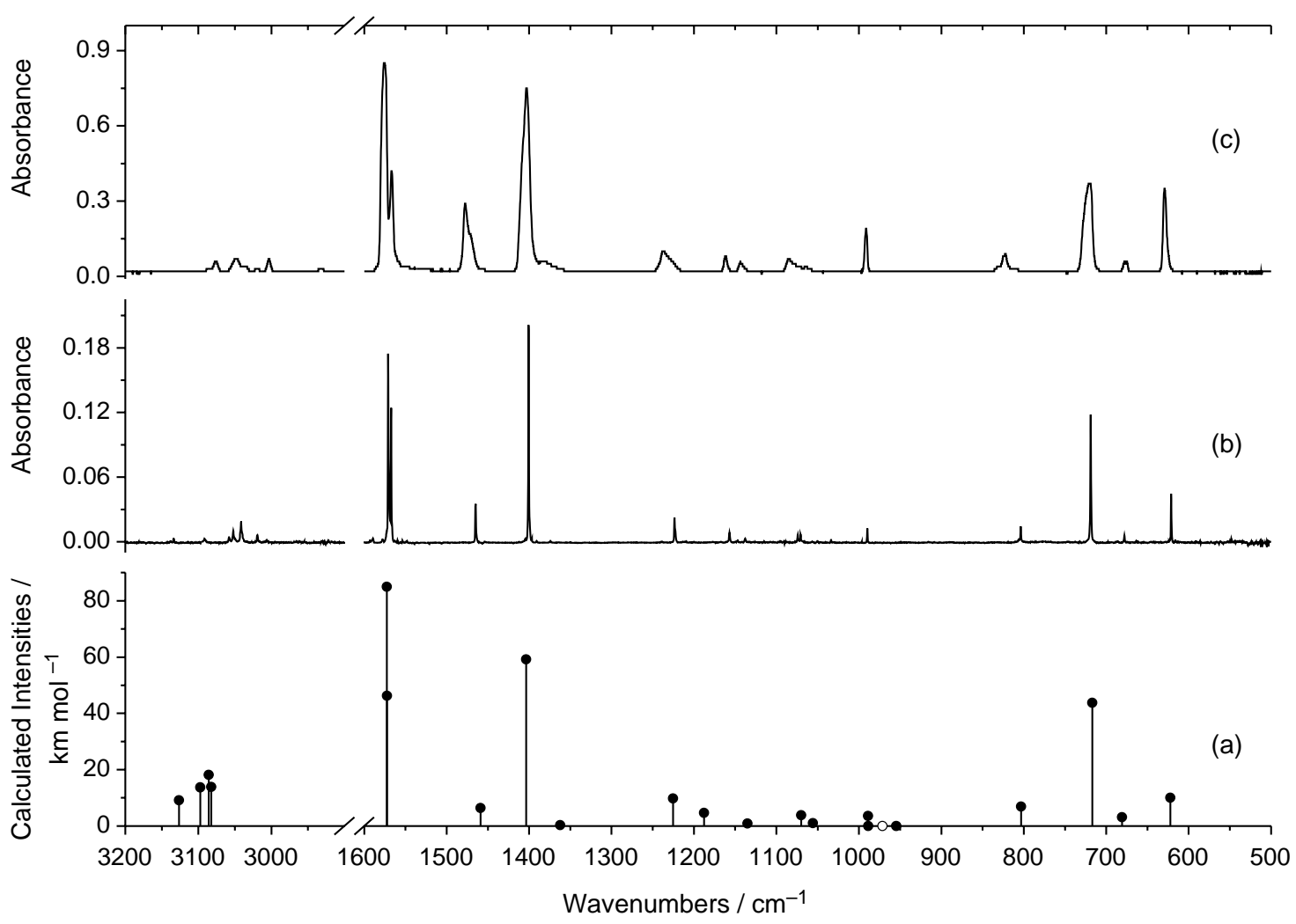

Fig. 3. Calculated infrared spectrum of pyrimidine monomer (a) and observed infrared spectra of pyrimidine isolated in an argon matrix at $10 \mathrm{~K}$ (b) and in the low temperature crystalline phase (c). In the calculated spectrum, the open circle indicates the position of the IR inactive mode. Calculated frequencies are scaled by a single factor 0.978 .

Martin [23]. There are essentially two factors contributing to this: (i) the high resolution and sensitivity of matrix-isolation spectroscopy, (ii) the possibility of direct comparison of the spectrum calculated for the monomer in vacuum with the purely vibrational, almost unperturbed spectrum obtained for the monomeric pyridazine in argon (which allows also to take advantage of strict applicability of symmetry considerations during the analysis of the spectra).

\subsection{Pyrimidine}

The IR spectra of pyrimidine monomer in an argon matrix and of the crystalline phase of the compound at low temperature $(10 \mathrm{~K})$ are shown in Fig. 3, together with the calculated spectrum. The results of normal coordinate analysis and band assignments are provided in Table 5. As for pyridazine, the vibrational modes of pyrimidine are named in the present work following the scheme adopted by Boese and Martin [23] (see also Table 5).

The spectrum obtained by us matches very closely the spectrum of monomer measured previously [34,35]. In the works by McCarthy et al [34,35]. a grating infrared spectrometer was used and main attention was paid to the spectral regions with strong absorptions. In the present study, a Fourier-transform spectrometer was used, allowing the characterization of the entire IR spectrum. As a result, two new fundamental absorptions, with respect to the studies [34,35], have been registered experimentally. These are modes (15) of the $\mathrm{B}_{2}$ symmetry and (6) of the $\mathrm{A}_{1}$ symmetry, with weak intrinsic intensities (less than $1 \mathrm{~km} \mathrm{~mol}^{-1}$, see Table 5). They absorb at 1374.0 and $1138.2 \mathrm{~cm}^{-1}$, respectively, and match well the calculated values 1362.2 and $1134.9 \mathrm{~cm}^{-1}$. In the spectrum of the crystalline pyrimidine at $10 \mathrm{~K}$, the corresponding bands have counterparts observed at 1380.9 and $1142.5 \mathrm{~cm}^{-1}$. In addition to these two fundamental vibrations, several new weak absorptions were registered, at 3133.4, 1979.5, 1955.6, 1391.0, 1146.7, $1034.1 \mathrm{~cm}^{-1}$. We attribute them to combination tones (Table 5). Observation of these new weak bands may be practically useful in simulations of anharmonic spectra of pyrimidine. Furthermore, because our spectra were obtained with better resolution than those of McCarthy et al., [34,35] we were able to clearly separate the bands in the $1580-1570 \mathrm{~cm}^{-1}$. This clear picture allowed to confirm the assignment for mode (13) of $\mathrm{B}_{2}$ symmetry and of mode (4) of $A_{1}$ symmetry. Although this assignment is opposite to that proposed both by Boese and Martin [23] and K.Berezin, Nechaev and El'kin [24], it is supported by comparison of experimental and predicted intensities of the bands in question. The $\mathrm{B}_{2}$ mode gives rise to a more intense band at $1570.5 \mathrm{~cm}^{-1}$, whereas the $A_{1}$ vibration has a slightly lower frequency and the band corresponding to it appears at $1567.3 \mathrm{~cm}^{-1}$ as a lower intensity absorption. 
Table 5

Calculated vibrational frequencies, intensities and potential energy distributions (PED) and observed infrared spectra for pyrimidine monomer isolated in an argon matrix and crystal phase (frequencies $(\nu)$ in $\mathrm{cm}^{-1}$ theoretical intensities $(I)$ in $\mathrm{km} \mathrm{mol}^{-1}$ )

\begin{tabular}{|c|c|c|c|c|c|c|c|c|}
\hline \multirow[t]{2}{*}{ Mode $^{a}$} & \multirow[t]{2}{*}{ Sym. } & \multicolumn{2}{|c|}{$\begin{array}{l}\text { Calculated [B3LYP/6-311++ } \\
\text { G(d, p)] }\end{array}$} & \multirow[t]{2}{*}{$\operatorname{PED}^{\mathrm{c}}(\%)$} & \multicolumn{2}{|c|}{$\begin{array}{l}\text { Monomer (infrared, Ar } \\
\text { matrix, } T=10 \mathrm{~K} \text { ) }\end{array}$} & \multicolumn{2}{|c|}{ Crystal $(T=10 \mathrm{~K})$} \\
\hline & & $\nu^{\mathrm{b}}$ & $I$ & & $\nu$ & $I^{\mathrm{d}}$ & $\nu$ & $I^{\mathrm{d}}$ \\
\hline $2 \mathrm{x}(4)$ & & & & & 3138.2 & 1.2 & & \\
\hline$(13)+(4)$ & & & & & 3133.4 & 2.2 & & \\
\hline (1) & $A_{1}$ & 3126.4 & 9.1 & $\nu$ (C5H9)(92.3) & 3091.4 & 4.5 & 3076.0 & 2.8 \\
\hline (2) & $A_{1}$ & 3097.6 & 13.7 & $\nu(\mathrm{C} 2 \mathrm{H} 7)(97.5)$ & 3057.4 & 4.0 & 3047.0 & 8.0 \\
\hline (12) & $\mathrm{B}_{2}$ & 3085.7 & 18.1 & $\nu(\mathrm{CH})_{\mathrm{as}}(99.6)$ & 3052.1 & 9.5 & & \\
\hline (3) & $\mathrm{A}_{1}$ & 3082.4 & 13.9 & $\nu(\mathrm{CH})_{\mathrm{s}}(91.3)$ & 3041.0 & 17.0 & 3035.4 & \\
\hline$(13)+(14)$ & & & & & 3019.2 & 4.4 & 3018.5 & 0.8 \\
\hline$(4)+(14)$ & & & & & 3006.4 & 1.5 & 3001.7 & 3.0 \\
\hline$(4)+(5)$ & & & & & 2921.0 & & 2930.2 & 1.4 \\
\hline $2 \mathrm{x}(8)$ & & & & & 1979.5 & 2.0 & & \\
\hline $2 \times(18)$ & & & & & 1955.6 & 3.5 & & \\
\hline (13) & $\mathrm{B}_{2}$ & 1572.4 & 85.0 & $\nu(\mathrm{CC})_{\mathrm{as}}(44.6)+\nu(\mathrm{NC})_{\mathrm{as}}^{1}(27.2)$ & 1570.5 & 75.4 & 1575.7 & 92.6 \\
\hline (4) & $\mathrm{A}_{1}$ & 1572.2 & 46.3 & $\nu(\mathrm{NC})_{\mathrm{s}}^{2}(45.1)+\delta(\mathrm{CH})_{\mathrm{s}}(22.8)+\nu(\mathrm{CC})_{\mathrm{s}}(19.9)$ & 1567.3 & 41.5 & 1566.0 & \\
\hline (14) & $\mathrm{B}_{2}$ & 1458.9 & 6.4 & $\delta(\mathrm{C} 2 \mathrm{H} 7)(33.4)+\delta(\mathrm{C} 5 \mathrm{H} 9)(23.2)+\nu(\mathrm{NC})^{2}{ }_{\mathrm{as}}(18.8)+\delta(\mathrm{CH})_{\mathrm{as}}(13.5)$ & 1464.8 & 15.2 & 1476.2 & 27.7 \\
\hline (5) & $A_{1}$ & 1403.6 & 59.2 & $\delta(\mathrm{CH})_{\mathrm{s}}(47.1)+\nu(\mathrm{NC})_{\mathrm{s}}^{1}(30.6)+\nu(\mathrm{NC})_{\mathrm{s}}^{2}(15.7)$ & 1400.6 & 72.5 & 1403.3 & 84.6 \\
\hline$(23)+(9)$ & & & & & 1391.0 & 0.3 & & \\
\hline (15) & $\mathrm{B}_{2}$ & 1362.2 & 0.3 & $\delta(\mathrm{C} 2 \mathrm{H} 7)(46.4)+\delta(\mathrm{CH})_{\mathrm{as}}(44.5)$ & 1374.0 & 0.3 & 1380.9 & 8.8 \\
\hline (16) & $\mathrm{B}_{2}$ & 1225.3 & 9.8 & $\nu(\mathrm{NC})^{1}{ }_{\text {as }}(55.2)+\delta(\mathrm{CH})_{\mathrm{as}}(30.0)+\delta(\mathrm{C} 5 \mathrm{H} 9)(13.7)$ & 1223.2 & 11.4 & 1236.5 & 13.9 \\
\hline (17) & $\mathrm{B}_{2}$ & 1187.7 & 4.6 & $\nu(\mathrm{NC})^{2}{ }_{\mathrm{as}}(60.4)+\nu(\mathrm{CC})_{\mathrm{as}}(21.1)$ & 1156.8 & 4.7 & 1160.8 & 3.4 \\
\hline$(22)+(24)$ & & & & & 1146.7 & 1.2 & & \\
\hline (6) & $A_{1}$ & 1134.9 & 0.9 & $\nu(\mathrm{NC})_{\mathrm{s}}^{1}(33.5)+\delta$ ring $1(24.1)+\delta(\mathrm{CH})_{\mathrm{s}}(19.4)+\nu(\mathrm{CC})_{\mathrm{s}}(12.6)$ & 1138.2 & 1.7 & 1142.5 & 2.9 \\
\hline (18) & $\mathrm{B}_{2}$ & 1069.8 & 3.8 & $\delta(\mathrm{C} 5 \mathrm{H} 9)(44.4)+\nu(\mathrm{NC})_{\text {as }}^{2}(22.9)+\nu(\mathrm{CC})_{\mathrm{as}}(21.6)$ & 1073.9 & 3.5 & 1083.7 & 10.0 \\
\hline (7) & $A_{1}$ & 1055.8 & 1.0 & $\nu(\mathrm{CC})_{\mathrm{s}}(46.8)+\delta \operatorname{ring} 1(38.2)+\delta(\mathrm{CH})_{\mathrm{s}}(10.1)$ & 1070.7 & 4.1 & 1064.0 & \\
\hline (8) & $\mathrm{A}_{1}$ & 988.8 & 3.5 & $\delta$ ring $1(37.3)+\nu(\mathrm{NC})_{\mathrm{s}}^{1}(24.5)+\nu(\mathrm{NC})_{\mathrm{s}}{ }_{\mathrm{s}}(23.2)+\nu(\mathrm{CC})_{\mathrm{s}}(14.8)$ & 989.5 & 4.1 & 991.1 & 6.6 \\
\hline (20) & $\mathrm{B}_{1}$ & 988.5 & 0.003 & $\gamma(\mathrm{C} 2 \mathrm{H} 7)(48.2)+\gamma(\mathrm{CH})_{\mathrm{s}}(46.1)+\gamma(\mathrm{C} 5 \mathrm{H} 9)(14.6)$ & & & & \\
\hline (10) & $\mathrm{A}_{2}$ & 971.3 & 0 & $\gamma(\mathrm{CH})_{\mathrm{as}}(106.8)$ & & & & \\
\hline (21) & $\mathrm{B}_{1}$ & 954.6 & 0.03 & $\gamma(\mathrm{C} 2 \mathrm{H} 7)(52.2)+\gamma(\mathrm{C} 5 \mathrm{H} 9)(41.6)+\gamma(\mathrm{CH})_{\mathrm{s}}(21.6)$ & & & & \\
\hline (22) & $\mathrm{B}_{1}$ & 803.0 & 6.9 & $\tau$ ring $1(39.5)+\gamma(\mathrm{C} 5 \mathrm{H} 9)(35.7)+\gamma(\mathrm{CH})_{\mathrm{s}}(25.8)$ & 803.1 & 8.2 & 831.7 & 9.0 \\
\hline (17)-(11) & & & & & & & 822.9 & \\
\hline (6)-(24) & & & & & & & 807.9 & \\
\hline (23) & $\mathrm{B}_{1}$ & 716.9 & 43.7 & $\tau$ ring $1(75.6)+\gamma(\mathrm{C} 5 \mathrm{H} 9)(13.6)$ & 719.2 & 49.4 & 720.5 & 44.1 \\
\hline (9) & $A_{1}$ & 680.7 & 3.1 & $\delta$ ring $2(89.8)$ & 677.7 & 2.9 & 675.6 & 2.6 \\
\hline (19) & $\mathrm{B}_{2}$ & 622.2 & 10.0 & $\delta$ ring $3(92.5)$ & 620.9 & 13.1 & 628.0 & 18.3 \\
\hline (11) & $\mathrm{A}_{2}$ & 397.9 & 0 & $\tau$ ring $2(106.7)$ & & & & \\
\hline (24) & $\mathrm{B}_{1}$ & 339.4 & 3.5 & $\tau$ ring $3(109.3)$ & & & & \\
\hline
\end{tabular}

${ }^{a}$ Numbering of modes follows that used by Boese and Martin [23].

b Theoretical positions of absorption bands were scaled down by a factor of 0.978 .

c PEDs lower than $10 \%$ are not included. Definition of symmetry coordinates is given in Table 2. See Fig. 1 for atom numbering. Theoretical results as symmetry and PEDs are not applicable to the crystal phase.

d Relative integrated intensities. 


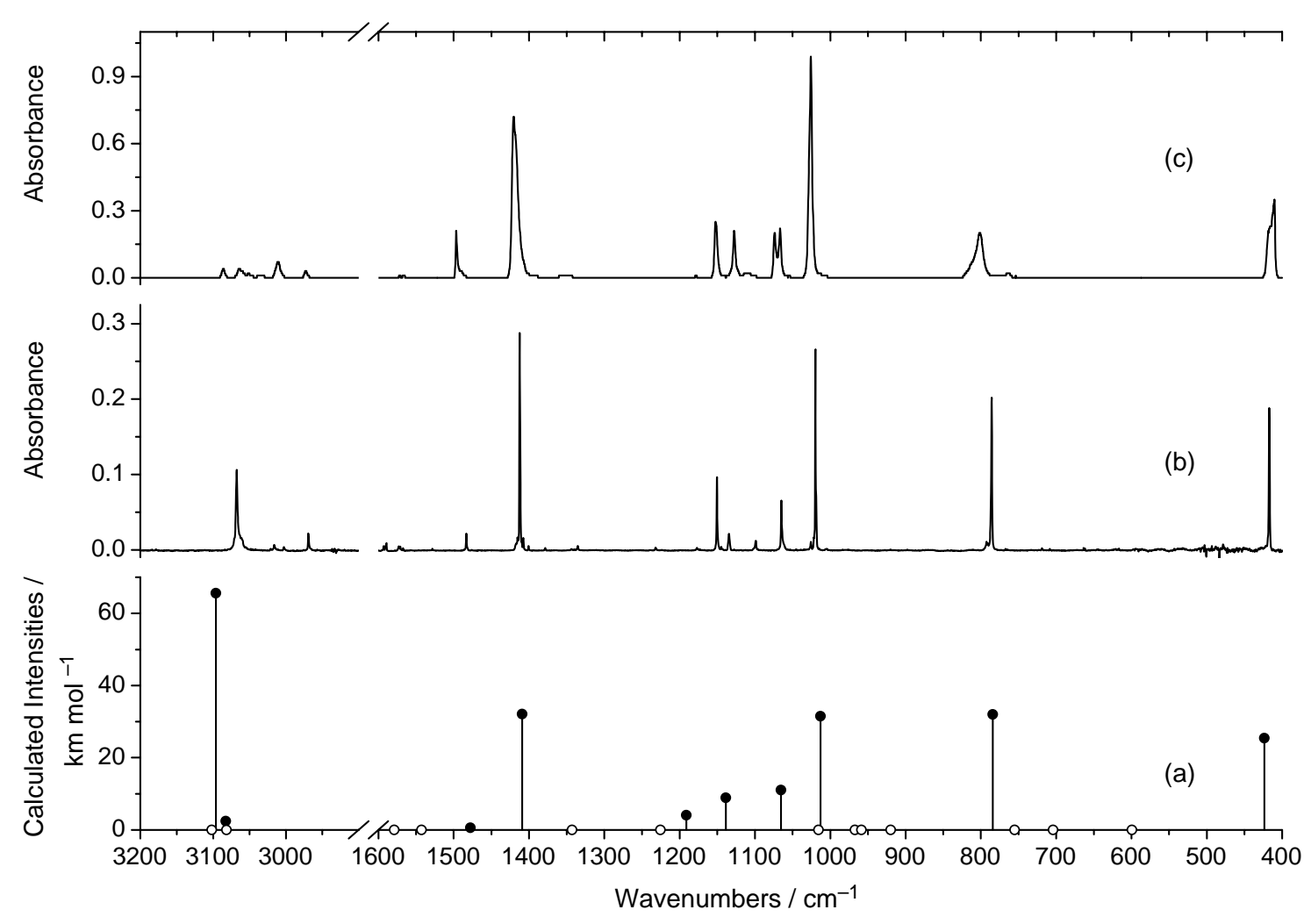

Fig. 4. Calculated infrared spectrum of pyrazine monomer (a) and observed infrared spectra of pyrazine isolated in an argon matrix at $10 \mathrm{~K}$ (b) and in the low temperature crystalline phase (c). In the calculated spectrum, open circles indicate the positions of the IR inactive modes. Calculated frequencies are scaled by a single factor 0.978 .

\subsection{Pyrazine}

The IR spectra collected for monomeric and crystalline pyrazine are presented in Fig. 4 and Table 6. The experimental spectra are compared with the results of DFT(B3LYP)/6$311++\mathrm{G}(\mathrm{d}, \mathrm{p})$ calculations carried out for the compound. Similarly to other diazines, the vibrations of pyrazine are designated in the current paper as in the work of Boese and Martin [23] (see Table 6).

When compared to the literature data $[21,29,45,46]$, in particular to the conclusions derived from the studies of the IR spectra of gaseous pyrazine [21], our results (both for the matrix-isolated compound and for the low temperature crystal) show essential discrepancies in the assignment of the modes (17) and (21) (of symmetry $B_{1 u}$ and $B_{2 u}$, respectively). For the other IR active modes, our results confirm previous assignments made on the basis of the gas-phase data $[21,23]$.

The fact that the assignment of mode (21) to a band at $1337 \mathrm{~cm}^{-1}$, as proposed by Billes, Mikosch and Holly [21], is not correct, has already been stressed by Boese and Martin [23] (the band at $1337 \mathrm{~cm}-{ }^{1}$ in the spectrum of gaseous pyrazine has a counterpart at $1335.3 \mathrm{~cm}^{-1}$ in the spectrum of the matrixisolated compound and should be ascribed to the (8) +(24) combination tone). Indeed, the present results show that the anharmonic calculations of Boese and Martin [23] provided a good estimation of the frequency of mode $(21), 1174 \mathrm{~cm}^{-1}$ [23], which fits nicely the frequencies observed for the corresponding band in the spectrum of the matrix-isolated compound $\left(1177.0 \mathrm{~cm}^{-1}\right)$ and in the spectrum of crystalline pyrazine at $10 \mathrm{~K}\left(1178.5 \mathrm{~cm}^{-1}\right)$. The frequency of mode (21), obtained in the scaled B3LYP/6-311+ $+\mathrm{G}(\mathrm{d}, \mathrm{p})$ harmonic calculation, is slightly overestimated $\left(1191.0 \mathrm{~cm}^{-1}\right.$; see Table 6). These observations might indicate that packing can induce some perturbation in the potential of this vibration, which in fact corresponds to the 'Kekule mode' associated with the dissociation of pyrazine to $2 \mathrm{HCN}+\mathrm{C}_{2} \mathrm{H}_{2}$ [23].

Regarding mode (17), the present study shows that it gives rise to a relatively intense band at $1150.5 \mathrm{~cm}^{-1}$ for the matrixisolated compound, which has a counterpart in the spectrum of the crystal at $10 \mathrm{~K}$ at $1152.7 \mathrm{~cm}^{-1}$. For pyrazine in the gaseous phase, the band due to this mode is observed at $1135 \mathrm{~cm}^{-1}$, i.e., at a somewhat lower frequency, which is indeed closer to the calculated values (anharmonic [23] and scaled harmonic frequencies are around 1136 and $1138 \mathrm{~cm}^{-1}$, respectively).

The assignment of the two $B_{2 g}$ modes, (9) and (10) (which are inactive in infrared for the monomer) was previously made on the basis of the Raman spectra of the melted compound [21], was also confirmed by analysis of the spectrum of the crystal at $10 \mathrm{~K}$, where weak bands at 966.6 and $754.0 \mathrm{~cm}^{-1}$ could be observed. These frequencies fit nicely the theoretically predicted values (958.6 and $755.0 \mathrm{~cm}^{-1}$; see Table 6) and are similar to the frequencies of the bands observed in the Raman spectrum of melted pyrazine (976 and $755 \mathrm{~cm}^{-1}$ ) [21].

A final note shall be here made regarding the assignment of the $\mathrm{CH}$ stretching bands in pyridazine, pyrimidine and pyrazine. It has been noticed that these modes are extensively 
Table 6

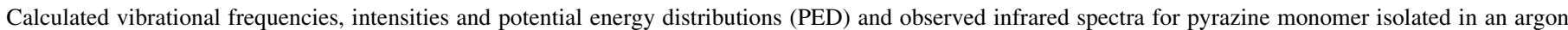
matrix and crystal phase (frequencies $(\nu)$ in $\mathrm{cm}^{-1}$, theoretical intensities $(I)$ in $\mathrm{km} \mathrm{mol}^{-1}$ )

\begin{tabular}{|c|c|c|c|c|c|c|c|c|c|}
\hline \multirow[t]{2}{*}{ Mode $^{a}$} & \multirow[t]{2}{*}{ Sym. } & \multicolumn{2}{|c|}{$\begin{array}{l}\text { Calculated [B3LYP/6- } \\
311++\mathrm{G}(\mathrm{d}, \mathrm{p})]\end{array}$} & \multirow[t]{2}{*}{$\operatorname{PED}^{\mathrm{b}}(\%)$} & \multicolumn{2}{|c|}{$\begin{array}{l}\text { Monomer (infrared, } \\
\text { Ar matrix, } T=10 \mathrm{~K} \text { ) }\end{array}$} & \multicolumn{2}{|c|}{ Crystal $(T=10 \mathrm{~K})$} & \multirow{2}{*}{$\begin{array}{c}\text { Vapor }^{\mathrm{c}} \\
\frac{[21-23]}{\nu}\end{array}$} \\
\hline & & $\nu^{\mathrm{d}}$ & $I$ & & $\nu$ & $I^{\mathrm{e}}$ & $\nu$ & $I^{\mathrm{e}}$ & \\
\hline (1) & $\mathrm{A}_{\mathrm{g}}$ & 3102.0 & 0 & $\nu(\mathrm{CH})_{\mathrm{s}}(99.2)$ & & & & & 3062 \\
\hline $2 x(12)$ & $\mathrm{A}_{\mathrm{g}}$ & & & & & & 3085.9 & 2.4 & \\
\hline (19) & $\mathrm{B}_{2 \mathrm{u}}$ & 3096.1 & 65.6 & $\nu(\mathrm{CH}){ }^{\prime}{ }_{\text {as }}(99.5)$ & 3067.7 & 42.6 & 3064.2 & 5.4 & 3069 \\
\hline (15) & $\mathrm{B}_{1 \mathrm{u}}$ & 3082.6 & 2.4 & $\nu(\mathrm{CH})^{\prime}{ }_{\text {as }}(99.7)$ & 3061.2 & & 3051.9 & & 3069 \\
\hline (11) & $\mathrm{B}_{3 \mathrm{~g}}$ & 3081.5 & 0 & $\nu(\mathrm{CH})_{\mathrm{as}}(100.0)$ & & & & & 3053 \\
\hline$(2)+(16)$ & $\mathrm{B}_{1 \mathrm{u}}$ & & & & 3021.1 & 0.5 & 3034.3 & 1.6 & \\
\hline$(12)+(16)$ & $\mathrm{B}_{2 \mathrm{u}}$ & & & & 3016.2 & 2.5 & 3011.2 & 5.1 & \\
\hline$(2)+(20)$ & $\mathrm{B}_{2 \mathrm{u}}$ & & & & 3002.9 & 1.1 & & & \\
\hline$(12)+(20)$ & $\mathrm{B}_{1 \mathrm{u}}$ & & & & 2969.1 & 4.4 & 2973.1 & 1.8 & \\
\hline$(6)+(9)$ & $\mathrm{B}_{2 \mathrm{u}}$ & & & & 1940.3 & 2.8 & & & \\
\hline$(6)+(8)$ & $\mathrm{B}_{1 \mathrm{u}}$ & & & & 1895.9 & 1.3 & & & \\
\hline$(9)+(23)$ & $\mathrm{B}_{1 \mathrm{u}}$ & & & & 1747.0 & 1.3 & & & \\
\hline$(8)+(23)$ & $\mathrm{B}_{2 \mathrm{u}}$ & & & & 1703.2 & 1.9 & & & \\
\hline (2) & $A_{g}$ & 1578.9 & 0 & $\nu(\mathrm{CC})_{\mathrm{s}}(44.1)+\delta(\mathrm{CH})_{\mathrm{s}}(26.1)+\nu(\mathrm{NC})_{\mathrm{s}}(22.3)$ & & & & & 1579 \\
\hline (12) & $\mathrm{B}_{3 \mathrm{~g}}$ & 1542.8 & 0 & $\nu(\mathrm{NC})_{\text {as }}(83.3)$ & & & & & 1522 \\
\hline (16) & $\mathrm{B}_{1 \mathrm{u}}$ & 1477.7 & 0.5 & $\delta(\mathrm{CH}){ }^{\prime}{ }_{\text {s }}(69.2)+\nu(\mathrm{NC}){ }^{\prime}{ }_{\text {as }}(30.3)$ & 1483.1 & 3.5 & 1496.5 & 7.5 & 1484 \\
\hline (20) & $\mathrm{B}_{2 \mathrm{u}}$ & 1409.0 & 32.1 & $\delta(\mathrm{CH}){ }_{\text {as }}(65.0)+\nu(\mathrm{CC})_{\text {as }}(27.0)$ & $\begin{array}{l}1415.3 \\
1412.2 \\
1407.8\end{array}$ & 45.5 & 1420.4 & 56.2 & 1413 \\
\hline$(23)+(5)$ & $\mathrm{B}_{3 \mathrm{u}}$ & & & & 1400.9 & 0.8 & & & \\
\hline$(9)+(24)$ & $\mathrm{B}_{1 \mathrm{u}}$ & & & & 1378.5 & 0.4 & & & \\
\hline (13) & $\mathrm{B}_{3 \mathrm{~g}}$ & 1342.7 & 0 & $\delta(\mathrm{CH})_{\mathrm{as}}(91.9)$ & & & 1351.1 & 2.0 & 1353 \\
\hline$(8)+(24)$ & $\mathrm{B}_{2 \mathrm{u}}$ & & & & 1335.3 & 1.1 & & & 1337 \\
\hline$(8)+(7)$ & $\mathrm{B}_{1 \mathrm{u}}$ & & & & 1231.8 & 0.7 & & & \\
\hline (3) & $A_{g}$ & 1225.5 & 0 & $\delta(\mathrm{CH})_{\mathrm{s}}(66.9)+\nu(\mathrm{NC})_{\mathrm{s}}(25.1)$ & & & & & 1235 \\
\hline$(21)$ & $\mathrm{B}_{2 \mathrm{u}}$ & 1191.0 & 4.1 & $\nu(\mathrm{NC})^{\prime}{ }_{\text {as }}(82.7)+\nu(\mathrm{CC})_{\mathrm{as}}(17.5)$ & 1177.0 & 0.6 & 1178.5 & 0.6 & $1174^{\mathrm{f}}$ \\
\hline (17) & $\mathrm{B}_{1 \mathrm{u}}$ & 1138.7 & 8.9 & $\nu(\mathrm{NC})^{\prime}{ }_{\text {as }}(51.5)+\delta(\mathrm{CH})^{\prime}{ }_{\text {as }}(26.7)+\delta \operatorname{ring} 1(21.7)$ & 1150.5 & 14.4 & 1152.7 & 10.0 & 1135 \\
\hline$(10)+(24)$ & $\mathrm{B}_{1 \mathrm{u}}$ & & & & 1144.6 & 1.0 & & & \\
\hline $2 x(7)+(24)$ & $\mathrm{B}_{3 \mathrm{u}}$ & & & & 1134.2 & 5.3 & 1128.3 & 7.0 & \\
\hline$(10)+(7)$ & $\mathrm{B}_{2 \mathrm{u}}$ & & & & 1099.2 & 3.0 & 1112.0 & 1.7 & \\
\hline (22) & $\mathrm{B}_{2 \mathrm{u}}$ & 1065.5 & 11.1 & $\nu(\mathrm{CC})_{\mathrm{as}}(55.1)+\delta(\mathrm{CH}){ }_{\mathrm{as}}(35.2)+\nu(\mathrm{NC}){ }_{\mathrm{as}}(9.6)$ & 1064.9 & 13.7 & $\begin{array}{l}1073.9 \\
1067.1\end{array}$ & 15.6 & 1063 \\
\hline (4) & $\mathrm{A}_{\mathrm{g}}$ & 1015.4 & 0 & $\nu(\mathrm{NC})_{\mathrm{s}}(53.2)+\nu(\mathrm{CC})_{\mathrm{s}}(40.2)$ & & & & & 1015 \\
\hline$(5)+(24)$ & $\mathrm{B}_{3 \mathrm{u}}$ & & & & 1025.8 & 2.0 & & & \\
\hline (18) & $\mathrm{B}_{1 \mathrm{u}}$ & 1012.9 & 31.5 & $\delta$ ring $1(77.7)+\nu(\mathrm{NC})^{\prime}{ }_{\text {as }}(18.1)$ & 1019.5 & 34.8 & 1025.0 & 42.1 & 1020 \\
\hline$(14)+(7)$ & $\mathrm{B}_{3 \mathrm{u}}$ & & & & 1004.4 & 0.8 & & & \\
\hline (6) & $A_{u}$ & 967.1 & 0 & $\gamma(\mathrm{CH})_{\mathrm{as}}(110.3)$ & & & & & $982^{f}$ \\
\hline (9) & $\mathrm{B}_{2 \mathrm{~g}}$ & 958.6 & 0 & $\gamma(\mathrm{CH})^{\prime}{ }_{\text {as }}(119.0)$ & & & 966.6 & 0.7 & 976 \\
\hline (8) & $\mathrm{B}_{1 \mathrm{~g}}$ & 919.7 & 0 & $\gamma(\mathrm{CH})^{\prime}{ }_{\text {as }}(100.0)$ & & & & & 925 \\
\hline (23) & $\mathrm{B}_{3 \mathrm{u}}$ & 784.1 & 32.0 & $\gamma(\mathrm{CH})_{\mathrm{s}}(107.1)$ & $\begin{array}{l}792.2 \\
785.6\end{array}$ & $\begin{array}{c}4.0 \\
32.0\end{array}$ & 802.1 & 24.4 & 785 \\
\hline$(24)+(7)$ & $\mathrm{B}_{3 \mathrm{~g}}$ & & & & & 3.8 & 764.1 & 3.8 & \\
\hline (10) & $\mathrm{B}_{2 \mathrm{~g}}$ & 755.0 & 0 & $\tau$ ring 1 (118.9) & & & 754.0 & & 755 \\
\hline (14) & $\mathrm{B}_{3 \mathrm{~g}}$ & 703.9 & 0 & $\delta$ ring $3(91.0)$ & & & & & 698 \\
\hline (5) & $A_{g}$ & 599.1 & 0 & $\delta$ ring $2(92.4)$ & & & & & 596 \\
\hline (24) & $\mathrm{B}_{3 \mathrm{u}}$ & 423.4 & 25.4 & $\tau$ ring $3(107.1)$ & 416.9 & 26.5 & 410.8 & 25.2 & 417 \\
\hline (7) & $\mathrm{A}_{\mathrm{u}}$ & 339.0 & 0 & $\tau$ ring $2(110.2)$ & & & & & $338^{\mathrm{f}}$ \\
\hline
\end{tabular}

a Numbering of modes follows that used by Boese and Martin [23].

b PEDs lower than $10 \%$ are not included. Definition of symmetry coordinates is given in Table 3 . See Fig. 1 for atom numbering. The theoretical results as symmetry and PEDs are not applicable to the crystal phase.

${ }^{c}$ Raman active bands were obtained for the melted compound [22]. Includes re-assignments made on the basis of the present results.

$\mathrm{d}$ Theoretical positions of absorption bands were scaled down by a factor of 0.978 .

e Relative integrated intensities.

${ }^{f}$ Calculated (anharmonic) [23].

involved in anharmonic interactions $[23,24]$ and a definitive assignment would imply extensive use of isotopic labeling, which is beyond the purposes of the present study. Despite being in general agreement with the majority of the previous studies, the assignments proposed in Tables 4-6 shall still be considered as tentative. It is also worth referring to briefly to the effects of aggregation on the spectra of the studied compounds. As discussed above, the strongest bands in the 
Table 7

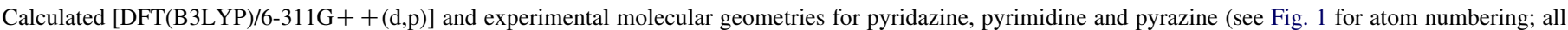
molecules were predicted to be planar: pyridazine $\left(\mathrm{C}_{2 \mathrm{v}}\right)$; pyrimidine $\left(\mathrm{C}_{2 \mathrm{v}}\right)$; pyrazine $\left.\left(\mathrm{D}_{2 \mathrm{~h}}\right)\right)$

\begin{tabular}{|c|c|c|c|c|c|c|c|c|}
\hline \multicolumn{3}{|l|}{ Pyridazine } & \multicolumn{3}{|l|}{ Pyrimidine } & \multicolumn{3}{|l|}{ Pyrazine } \\
\hline Parameter & Calculated & $\begin{array}{l}\text { Experimental } \\
\left(r_{\alpha}^{0}\right)[25]\end{array}$ & Parameter & Calculated & $\begin{array}{l}\text { Experimental } \\
\left(r_{\mathrm{a}}\right)[36]\end{array}$ & Parameter & Calculated & $\begin{array}{l}\text { Experimental } \\
\left(r_{\alpha}\right)[41]\end{array}$ \\
\hline \multicolumn{9}{|c|}{ Bond lengh/pm } \\
\hline $\mathrm{N} 1-\mathrm{N} 2$ & 133.12 & 133.70 & $\mathrm{~N} 1-\mathrm{C} 2$ & 133.52 & 134.0 & $\mathrm{~N} 1-\mathrm{C} 2$ & 133.49 & 133.69 \\
\hline $\mathrm{N} 2-\mathrm{C} 3$ & 133.35 & 133.79 & $\mathrm{C} 2-\mathrm{N} 3$ & 133.52 & 134.0 & $\mathrm{C} 2-\mathrm{C} 3$ & 139.46 & 139.83 \\
\hline $\mathrm{C} 3-\mathrm{C} 4$ & 139.64 & 140.00 & $\mathrm{~N} 3-\mathrm{C} 4$ & 133.64 & 134.0 & $\mathrm{C} 3-\mathrm{N} 4$ & 133.49 & 133.69 \\
\hline $\mathrm{C} 4-\mathrm{C} 5$ & 138.16 & 138.46 & $\mathrm{C} 4-\mathrm{C} 5$ & 139.10 & 134.0 & N4-C5 & 133.49 & 133.69 \\
\hline C5-C6 & 139.64 & 140.00 & C5-C6 & 139.10 & 139.3 & $\mathrm{C} 5-\mathrm{C} 6$ & 139.46 & 139.86 \\
\hline C6-N1 & 133.35 & 133.79 & C6-N1 & 133.64 & 139.3 & C6-N1 & 133.49 & 133.69 \\
\hline $\mathrm{C} 3-\mathrm{H} 7$ & 108.50 & 107.87 & $\mathrm{C} 2-\mathrm{H} 7$ & 108.60 & 109.9 & $\mathrm{C} 2-\mathrm{H} 7$ & 108.60 & 109.36 \\
\hline $\mathrm{C} 4-\mathrm{H} 8$ & 108.37 & 107.07 & $\mathrm{C} 4-\mathrm{H} 8$ & 108.65 & 109.9 & $\mathrm{C} 3-\mathrm{H} 8$ & 108.60 & 109.36 \\
\hline C5-H9 & 108.37 & 107.07 & C5-H9 & 108.30 & 109.9 & C5-H9 & 108.60 & 109.36 \\
\hline C6-H10 & 108.50 & 107.87 & C6-H10 & 108.65 & 109.9 & C6-H10 & 108.60 & 109.36 \\
\hline \multicolumn{9}{|c|}{ Bond angle/degree } \\
\hline $\mathrm{N} 1-\mathrm{N} 2-\mathrm{C} 3$ & 119.50 & 119.38 & $\mathrm{~N} 1-\mathrm{C} 2-\mathrm{N} 3$ & 127.02 & 127.6 & $\mathrm{~N} 1-\mathrm{C} 2-\mathrm{C} 3$ & 121.98 & 122.2 \\
\hline $\mathrm{N} 2-\mathrm{C} 3-\mathrm{C} 4$ & 123.62 & 123.76 & $\mathrm{C} 2-\mathrm{N} 3-\mathrm{C} 4$ & 115.99 & 115.5 & $\mathrm{C} 2-\mathrm{C} 3-\mathrm{N} 4$ & 121.98 & 122.2 \\
\hline C3-C4-C5 & 116.88 & 116.86 & $\mathrm{~N} 3-\mathrm{C} 4-\mathrm{C} 5$ & 122.22 & 122.3 & $\mathrm{C} 3-\mathrm{N} 4-\mathrm{C} 5$ & 116.05 & 115.4 \\
\hline $\mathrm{C} 4-\mathrm{C} 5-\mathrm{C} 6$ & 116.88 & 116.86 & $\mathrm{C} 4-\mathrm{C} 5-\mathrm{C} 6$ & 116.56 & 116.8 & $\mathrm{~N} 4-\mathrm{C} 5-\mathrm{C} 6$ & 121.98 & 122.2 \\
\hline C5-C6-N1 & 123.62 & 123.76 & C5-C6-N1 & 122.22 & 122.3 & C5-C6-N1 & 121.98 & 122.2 \\
\hline C6-N1-N2 & 119.50 & 119.38 & C6-N1-C2 & 115.99 & 115.5 & C6-N1-C2 & 116.05 & 115.4 \\
\hline $\mathrm{N} 2-\mathrm{C} 3-\mathrm{H} 7$ & 114.96 & 114.91 & $\mathrm{~N} 1-\mathrm{C} 2-\mathrm{H} 7$ & 116.49 & 116.2 & $\mathrm{~N} 1-\mathrm{C} 2-\mathrm{H} 7$ & 117.12 & 116.3 \\
\hline $\mathrm{C} 3-\mathrm{C} 4-\mathrm{H} 8$ & 120.85 & 120.67 & N3-C4-H8 & 116.52 & 115.3 & $\mathrm{C} 2-\mathrm{C} 3-\mathrm{H} 8$ & 120.90 & \\
\hline C4-C5-H9 & 122.26 & & $\mathrm{C} 4-\mathrm{C} 5-\mathrm{H} 9$ & 121.72 & 121.6 & N4-C5-H9 & 117.12 & 116.3 \\
\hline C5-C6-H10 & 121.41 & & C5-C6-H10 & 121.25 & & C5-C6-H10 & 120.90 & \\
\hline
\end{tabular}

IR spectra of pyridazine, pyrimidine and pyrazine are due to normal modes involving $\delta \mathrm{CH}$ and $\gamma \mathrm{CH}$ vibrations. In some cases also the ring stretching and ring out of plane deformations contribute to the normal modes giving rise to these strong IR absorptions. Upon association, alongside the general broadening of the IR bands, shifts of their spectral positions were observed. The most pronounced are the shifts of the bands due to $\gamma \mathrm{CH}$ vibrations, which appear in the spectra of the crystalline diazines at frequencies higher by $15-20 \mathrm{~cm}^{-1}$, with respect to the positions of these bands in the spectra of the corresponding monomers. In some cases, the spectral sifts of the bands due to $\delta \mathrm{CH}$ vibrations towards higher frequencies are also significant $\left(3-12 \mathrm{~cm}^{-1}\right)$, but the $\gamma \mathrm{CH}$ vibrations are usually coupled with ring stretching vibrations and this coupling makes the shifts of the band frequencies less characteristic.

\subsection{Spectra-structure correlations}

The structures calculated (at the DFT(B3LYP)/6-311++ $\mathrm{G}(\mathrm{d}, \mathrm{p})$ level) for pyridazine, pyrimidine and pyrazine are provided in Table 7 and compared with available experimental data $[25,36,41]$. In Table 8, the CC, $\mathrm{NN}$ and $\mathrm{CN}$ bond lengths are correlated with the corresponding Mulliken $\pi$ overlap populations and the relevant stretching vibrational frequencies. From these tables the following general conclusions can be drawn:

(i) The values of the calculated bond lengths of the rings clearly reveal that the electron delocalization is less pronounced in pyridazine as in the other two molecules (pyridazine shows the longest and the shortest $\mathrm{CC}$ bonds - respectively, C3C4/C5C6 and C4C5), i.e., this molecule must behave as a less aromatic species.

(ii) The bond lengths and Mulliken $\pi$ overlap populations in pyridazine ring, as well as the ((C4C5) $\left(1572.9 \mathrm{~cm}^{-1}\right)$ and $\left((\mathrm{NN})\left(967.3 \mathrm{~cm}^{-1}\right)\right.$ frequencies consistently indicate that the contribution of canonic form where the $\mathrm{C} 4 \mathrm{C} 5$ and $\mathrm{NN}$ bonds correspond to double and single bonds, respectively, is considerably more important for the structure of this molecule than the alternative canonic form where the double bond characters of these two bonds are the opposite.

(iii) The average $\mathrm{CC}$ stretching frequencies for the three molecules show a good general agreement with the structure data and Mulliken $\pi$ overlap populations, attaining a maximum value for the C4C5 vibration in pyridazine $\left(1572.9 \mathrm{~cm}^{-1}\right)$, which is the shortest $\mathrm{CC}$ bond length among all $\mathrm{CC}$ bond lengths in the studied compounds, and its minimum value $\left(1243.4 \mathrm{~cm}^{-1}\right)$ for the CC stretching modes associated with the two longest $\mathrm{CC}$ bonds in the same molecule; both in pyrazine and pyrimidine, where the $\mathrm{CC}$ bond lengths are in between the values observed for the two types of $\mathrm{CC}$ bonds in pyridazine, the average ((CC) frequency value $\left(\approx 1320 \mathrm{~cm}^{-1}\right)$ is also between the values found for pyridazine.

(iv) On the other hand, the $\mathrm{CN}$ bonds in all the studied molecules have very similar lengths; the frequencies of $((\mathrm{CN})$ vibrations (which mix extensively with other 
Table 8

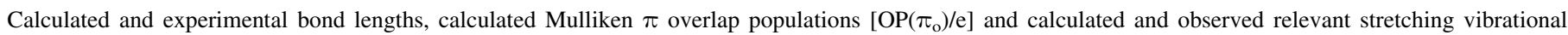
frequencies (monomers isolated in an argon matrices at $10 \mathrm{~K}$ ), for pyridazine, pyrimidine and pyrazine

\begin{tabular}{|c|c|c|c|c|c|c|}
\hline & \multicolumn{6}{|c|}{ Pyridazine $\left(\mathrm{C}_{2 \mathrm{v}}\right.$ symmetry $)$} \\
\hline & \multicolumn{2}{|c|}{ Bond length/pm } & \multirow[t]{2}{*}{$\mathrm{OP}\left(\pi_{\mathrm{o}}\right) / \mathrm{e}$} & \multirow[t]{2}{*}{$\nu_{\text {calc }} / \mathrm{cm}^{-1}$} & \multirow[t]{2}{*}{$\nu_{\mathrm{exp}} / \mathrm{cm}^{-1}$} & \multirow{2}{*}{$\begin{array}{l}\nu_{\text {exp }} / \mathrm{cm}^{-1} \\
\text { (average) }\end{array}$} \\
\hline & Cal. & Exp. [25] & & & & \\
\hline NN & 133.12 & 133.70 & 0.237 & 986.3 & 967.3 & 967.3 \\
\hline \multirow[t]{2}{*}{$\mathrm{CN}$} & 133.35 & 133.79 & 0.287 & $1566.0\left(\mathrm{~B}_{2}\right)$ & 1563.3 & $1360.6^{\mathrm{a}}$ \\
\hline & & & & $1155.3\left(\mathrm{~A}_{1}\right)$ & not observed & \\
\hline \multirow[t]{2}{*}{$\mathrm{CC}$} & 139.64 & 140.00 & 0.262 & $1443.6\left(\mathrm{~A}_{1}\right)$ & 1441.3 & 1243.4 \\
\hline & & & & $1059.4\left(\mathrm{~B}_{2}\right)$ & 1045.5 & \\
\hline \multirow[t]{4}{*}{$\mathrm{C}=\mathrm{C}$} & 138.16 & 138.46 & 0.328 & 1571.0 & 1572.9 & 1572.9 \\
\hline & \multicolumn{6}{|c|}{ Pyrimidine $\left(\mathrm{C}_{2 \mathrm{v}}\right.$ symmetry $)$} \\
\hline & \multicolumn{2}{|c|}{ Bond length/pm } & $\mathrm{OP}\left(\pi_{\mathrm{o}}\right) / \mathrm{e}$ & $\nu_{\text {calc }} / \mathrm{cm}^{-1}$ & $\nu_{\text {exp }} / \mathrm{cm}^{-1}$ & $\nu_{\text {exp }} / \mathrm{cm}^{-1}$ \\
\hline & Cal. & Exp. [36] & & & & \\
\hline \multirow[t]{2}{*}{$\mathrm{CN}$} & 133.52 & 134.0 & 0.279 & $1403.6\left(\mathrm{~A}_{1}\right)$ & 1400.6 & 1311.9 \\
\hline & & & & $1225.3\left(\mathrm{~B}_{2}\right)$ & 1223.2 & \\
\hline \multirow[t]{2}{*}{$\mathrm{C} 2 \mathrm{~N}$} & 133.64 & 134.0 & 0.267 & $1572.2\left(\mathrm{~A}_{1}\right)$ & 1567.3 & 1362.1 \\
\hline & & & & $1187.7\left(\mathrm{~B}_{2}\right)$ & 1156.8 & \\
\hline \multirow[t]{5}{*}{$\mathrm{CC}$} & 139.10 & 139.3 & 0.282 & $1572.4\left(\mathrm{~B}_{2}\right)$ & 1570.5 & 1320.6 \\
\hline & & & & $1055.8\left(\mathrm{~A}_{1}\right)$ & 1070.7 & \\
\hline & \multicolumn{6}{|c|}{ Pyrazine ( $\mathrm{D}_{2 \mathrm{~h}}$ symmetry) } \\
\hline & \multicolumn{2}{|c|}{ Bond length/pm } & $\mathrm{OP}\left(\pi_{\mathrm{o}}\right) / \mathrm{e}$ & $\nu_{\text {calc. }} / \mathrm{cm}^{-1}$ & $\nu_{\text {exp }} / \mathrm{cm}^{-1}$ & $\begin{array}{l}\nu_{\text {exp }} / \mathrm{cm}^{-1} \\
\text { (average) }\end{array}$ \\
\hline & Cal. & Exp. [41] & & & & \\
\hline \multirow[t]{4}{*}{$\mathrm{CN}$} & 133.49 & 133.69 & 0.276 & $1542.8\left(\mathrm{~B}_{3 \mathrm{~g}}\right)$ & Not observed & $1221.0^{\mathrm{a}}$ \\
\hline & & & & $1138.7\left(\mathrm{~B}_{1 \mathrm{u}}\right)$ & 1177.0 & \\
\hline & & & & $1191.0\left(\mathrm{~B}_{2 \mathrm{u}}\right)$ & 1150.5 & \\
\hline & & & & $1015.4\left(\mathrm{~A}_{\mathrm{g}}\right)$ & Not observed & \\
\hline \multirow[t]{2}{*}{$\mathrm{CC}$} & 139.46 & 139.86 & 0.292 & $1578.9\left(\mathrm{~A}_{\mathrm{g}}\right)$ & Not observed & $1322.0^{\mathrm{a}}$ \\
\hline & & & & $1065.5\left(\mathrm{~B}_{2 \mathrm{u}}\right)$ & 1064.9 & \\
\hline
\end{tabular}

\footnotetext{
${ }^{a}$ Average frequency value for this type of vibration estimated taking into consideration both experimental data and calculated frequencies
}

vibrations, in particular with $\delta(\mathrm{CH})$ in plane bending modes- see also Tables $4-6$ ) seem not to correlate in a simple way with the structural data.

Additional calculations have been performed on all three molecules to find the diagonal elements of the force constant matrix for the $\mathrm{X}-\mathrm{Y}$ stretching vibrations, where $\mathrm{X}, \mathrm{Y}$ are heavy atoms $(\mathrm{N}, \mathrm{C})$. In this way, force constants for every particular stretching vibration have been found. The obtained values (mdyn $\AA^{-1}$ ) are equal to 7.6208 (N1C2) and 6.6881 (C2C3) in pyrazine; 7.4534 (N1C2), 7.6073 (N3C4) and 6.9679 (C4C5) in pyrimidine; 6.1569 (N1N2), 7.3055 (N2C3), 6.7693 (C3C4) and 7.5425 (C4C5) in pyridazine. In general these values say the same as the data in Table 8, namely that the $\mathrm{NN}$ bond in pyridazine can be described as an essentially single bond, while the opposite $\mathrm{C} 4 \mathrm{C} 5$ bond as having a relatively large double bond character.

\subsection{Photochemical transformations}

All studied diazines have been subjected to UV irradiation with the primary purpose to find out whether their unimolecular photoisomerization was possible. Two types of sources of UV light were used in these experiments. Matrices were irradiated either with a high-pressure mercury lamp fitted with a filter (UG 11) transmitting light with $(\lambda>270 \mathrm{~nm})$ or with a pulsed excimer laser emitting light at $308 \mathrm{~nm}$. Under present experimental conditions only pyrazine reacted to produce another diazine.

The results of irradiation of matrix-isolated pyrazine with each of the UV light sources are presented in Fig. 5. Exposure of the matrices to both continuous-wave and pulsed UV radiation induced phototransformations of pyrazine molecules. An apparent feature observed in the IR spectra recorded after UV irradiation was the appearance in them of a set of new 


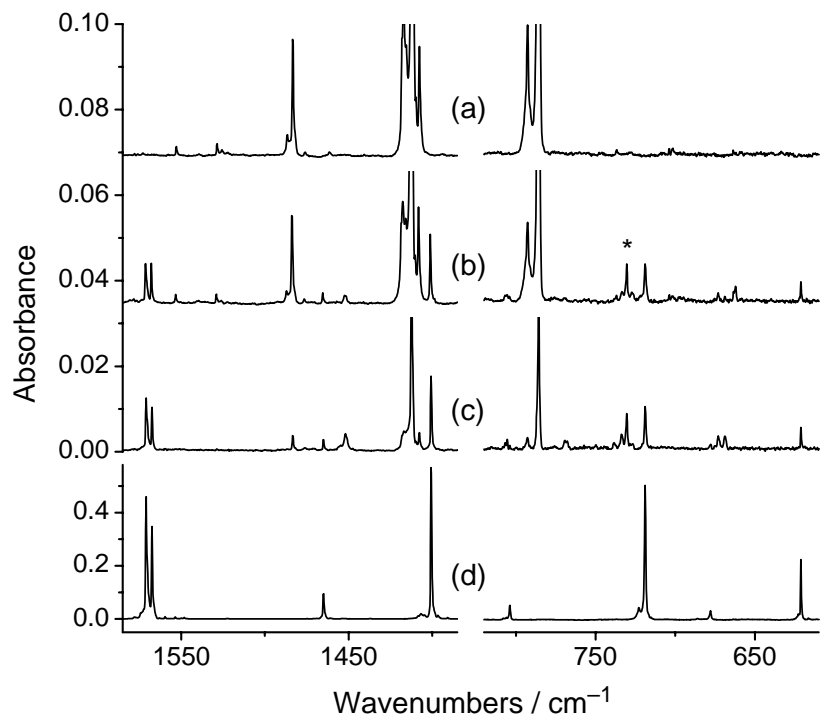

Fig. 5. Fragments of the infrared spectra of pyrazine isolated in an Ar matrix: (a) recorded after deposition of the matrix; (b) recorded after $3 \mathrm{~h}$ of irradiation with high pressure mercury lamp fitted with a cut-off filter transmitting light with $\lambda>270 \mathrm{~nm}$; (c) recorded (in a separate experiment) after $20 \mathrm{~min}$ of irradiation with a pulsed excimer laser $\lambda=308 \mathrm{~nm}$; (d) corresponding fragments of the spectrum of pyrimidine isolated in an Ar matrix. The asterisk indicates the band (at $730 \mathrm{~cm}^{-1}$ ) that should be assigned to the bending vibration of the $\mathrm{HCN}$ photoproduct.

bands, which can be unequivocally assigned to pyrimidine. The comparison of the new bands of the photoproduct(s) generated from pyrazine with the experimental spectrum of pyrimidine (recorded in a separate experiment) leaves no doubt about the identification of pyrimidine as a photoproduct of unimolecular photochemical transformations of pyrazine. All the bands observed in the experimental spectrum of pyrimidine are found in the spectrum of UV irradiated pyrazine at exactly the same frequencies (see Fig. 5). Also the relative intensities of the bands ascribable to the pyrimidine photoproduct are the same as in the spectrum of pyrimidine recorded after deposition of a matrix containing monomers of this compound. These observations confirm the reports of Lahmani and Ivanoff $[54,55]$ on detection of the pyrimidine photoproduct generated upon exposure of gaseous pyrazine to UV radiation.

The most plausible mechanism of the phototransformation of pyrazine into pyrimidine involves intermediacy of a benzvalene-like transient (see Fig. 6). The intermediate can, in turn, be created from prefulvene diradical, which is believed to be a primary photoproduct in the photochemistry of benzene and pyrazine [56-59].

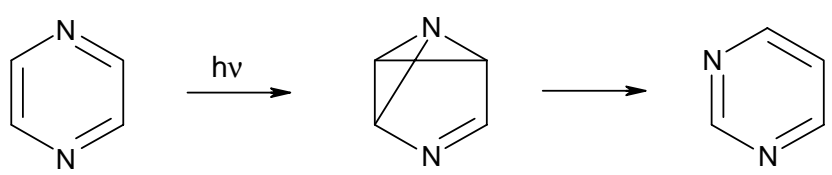

Fig. 6. The most probable way of phototransformation of pyrazine into pyrimidine.
The experiments on UV irradiation of matrix-isolated pyrazine have shown that the pyrazine pyrimidine phototransformation is not the sole process consuming the pyrazine substrate. Clear signatures of breaking of the pyrazine ring with evolution of $\mathrm{HCN}$ were also observed (see Fig. 5). The processes of photofragmentation of pyrazine involving generation of translationally hot $\mathrm{HCN}$ were previously investigated as a model of energy transfer following UV excitations of aromatic heterocyclic molecules $[60,61]$.

UV irradiation experiments were carried out also for other two diazines: pyrimidine and pyridazine. In the first case, although the pyrimidine substrate was consumed upon UV irradiation, neither pyridazine nor pyrazine product was detected on the basis of the IR spectra recorded after exposure to UV light. For pyridazine, no changes of the IR spectrum were observed, even when the matrices were irradiated with short-wavelength $(\lambda>200 \mathrm{~nm})$ UV light.

\section{Conclusion}

Infrared spectra of pyrazine and pyridazine isolated in lowtemperature argon matrices are reported in the present work for the first time, along with the spectra of pyrimidine obtained under the same experimental conditions. The vibrationally well-resolved spectra of diazines isolated in Ar matrices are particularly useful (because of resolution and simplicity of the spectra) for an assignment assisted by a comparison with the results of theoretical simulations. At present it seems that, for the molecules of the size of pyrazine, pyrimidine and pyridazine (each built of 10 atoms), the best set of theoretical data is provided by a combination of anharmonic (but lacking intensities) and harmonic (but providing intensities) approaches. Comparison of the experimental spectra with the theoretical frequencies (in some cases corrected for anharmonicity) and theoretical relative intensities of the IR bands, led to a reliable assignment presented in the current work, for the three diazines.

The present spectral data allowed carrying out structural correlations in the series of three diazines. The observed frequencies of the IR bands due to $\mathrm{CC}$ and $\mathrm{CN}$ stretching vibrations, calculated and experimental bond lengths, calculated Mulliken $\pi$ overlap populations, as well as the calculated harmonic force constants were used in the analysis of the electronic structure of the studied molecules. Among the three diazines, pyridazine was found to be significantly less aromatic than pyrimidine and pyrazine.

The experimental investigation on the effects of UV irradiation of diazines isolated in low-temperature argon matrices, carried out in the present work, allowed observation of the phototransformation of pyrazine monomer into pyrimidine. The pyrimidine photoproduct was identified unambiguously by a direct comparison of the spectrum growing upon UV irradiation of pyrazine with a spectrum of pyrimidine recorded in a separate experiment. 


\section{Acknowledgements}

The authors acknowledge the Portuguese Science Foundation (FCT-POCTI/QUI/59019/2004 and POCTI/QUI/58937/2004) and FEDER for financial support. S.B. thanks FCT for the Grant SFRH/BD/16119/2004 and to the Centre of Excellence ASPECT financed by the European Commission within the contract G6MA-CT-2002-04021. I.D.R. acknowledges FCT for the Grant SFRH/BPD/1661/2000.

\section{References}

[1] R. Barnes, R.C.B. Gore, U. Liddel, V.Z. Williams, Infrared Spectroscopy, Reinhold, New York, 1944, p. 97.

[2] I.A. Brownlie, J. Chem. Soc. (1950) 3062.

[3] L.N. Short, H.W. Thompson, J. Chem. Soc. (1952) 168.

[4] V. Schomaker, L. Pauling, J. Am. Chem. Soc. 61 (1939) 1769.

[5] F.M. Uber, J. Chem. Phys. 9 (1941) 777.

[6] F. Halverson, R.C. Hirt, J. Chem. Phys. 17 (1949) 1165.

[7] F. Halverson, R.C. Hirt, J. Chem. Phys. 19 (1951) 711.

[8] B.J. Fax, Near Ultraviolet Absorption Spectra of Pyridine-Pyridine- $\mathrm{d}_{5}$, and the Diazines under High Dispersion, PhD Thesis, Massachusetts Institute of Technology, 1950.

[9] M. Ito, R. Shimada, T. Kuraishi, W. Mizushima, J. Chem. Phys. 25 (1956) 597.

[10] R.C. Lord, A.L. Marston, F.A. Miller, Spectrochim. Acta 9 (1957) 113.

[11] V.I. Berezin, Opt. Spectrosc. USSR 18 (1965) 71.

[12] H.D. Stidham, J.V. Tucci, Spectrochim. Acta A23 (1967) 2233.

[13] A.D. Jordan, C. Parmente, Chem. Phys. Lett. 16 (1972) 437.

[14] P.J. Chappell, I.G. Ross, Chem. Phys. Lett. 43 (1976) 440.

[15] Y. Ozono, Y. Nibu, H. Shimada, R. Shimada, Bull. Chem. Soc. Jpn 59 (1986) 2997.

[16] K.B. Wiberg, J. Mol. Struct. 224 (1990) 61.

[17] K.B. Wiberg, D. Nakaji, C.M. Breneman, J. Am. Chem. Soc. 111 (1989) 4178.

[18] A. Navarro, J. Vázquez, M. Montejo, J.J.L. González, G.J. Kearley, Chem. Phys. Lett. 361 (2002) 483.

[19] A.R. Berces, P.G. Szalay, I. Magdo, G. Fogarasi, J. Phys. Chem. 97 (1993) 1356

[20] F. Billes, H. Mikosch, Acta Chim. Hung. 130 (1993) 901.

[21] F. Billes, H. Mikosch, S. Holly, Theochem 423 (1998) 225.

[22] J.M.L. Martin, C. Van Alsenoy, J. Phys. Chem. 100 (1996) 6973.

[23] A.D. Boese, J.M.L. Martin, J. Phys. Chem. A 108 (2004) 3085.

[24] K.V. Berezin, V.V. Nechaev, P.M. El'kin, Russ. J. Phys. Chem. 79 (2005) 425 .

[25] S. Cradock, C. Purves, D.W.H. Rankin, J. Mol. Struct. 220 (1990) 193.

[26] A.J. Blake, D.W.H. Rankin, Acta Crystallogr. C 47 (1991) 1933.

[27] J.D. Simmons, K.K. Innes, J. Mol. Spectrosc. 13 (1964) 435.

[28] G. Sbrana, G. Adembri, S. Califano, Spectrochim. Acta 22 (1966) 1831.

[29] K.K. Innes, I.G. Ross, W.R. Moomaw, J. Mol. Spectrosc. 132 (1988) 492.

[30] A. Navarro, M. Fernandez Gómez, J.J.L. Gonzaléz, M.P. Fernandez Liencres, E.M. Martizez Torres, J. Tomkinson, G.I. Kearley, J. Phys. Chem. A 103 (1999) 5833.

[31] A. Navarro, J. Vázquez, M. Montejo, J.J.L. González, G.J. Kearley, Chem. Phys. Lett. 361 (2002) 483.

[32] K.V. Berezin, V.V. Nechaev, P.M. El'kin, Opt. Spectrosc. 97 (2004) 201.
[33] A. Destexhe, J. Smets, L. Adamowicz, G. Maes, J. Phys. Chem. 98 (1994) 1506.

[34] W. McCarthy, J. Smets, L. Adamowicz, A.M. Plokhotnichenko, E.D. Radchenko, G.G. Sheina, S.G. Stepanian, Mol. Phys. 91 (1997) 513.

[35] W. McCarthy, A.M. Plokhotnichenko, E.D. Radchenko, J. Smets, D.M.A. Smith, S.G. Stepanian, L. Adamowicz, J. Phys. Chem. A 101 (1997) 7208.

[36] L. Fernholt, C. Römming, Acta Chem. Scand. A 32 (1978) 271.

[37] Z. Kisiel, L. Pszczolkowski, J.C. Lopez, J.L. Alonso, A. Maris, W. Caminati, J. Mol. Spectrosc. 195 (1999) 332.

[38] P.J. Wheatley, Acta Crystallogr. 13 (1960) 80.

[39] V. Schomaker, L. Pauling, J. Am. Chem. Soc. 61 (1939) 1769.

[40] P.J. Wheatley, Acta Crystallogr. 10 (1957) 182.

[41] B.J.M. Bormans, G. de With, F.C. Mijlhoff, J. Mol. Struct. 42 (1977) 121.

[42] S. Califano, G. Adembri, G. Sbrana, Spectrochim. Acta 20 (1964) 385.

[43] D.B. Scully, Spectrochim. Acta 17 (1961) 233.

[44] M.A. Montañez, I.L. Tocón, J.C. Otero, J.I. Marcos, J. Mol. Struct. 482 483 (1999) 201.

[45] J.F. Arenas, J.T. Lopez Navarrete, J.C. Otero, J.I. Marcos, J. Chem. Soc., Faraday Trans. 281 (1985) 405.

[46] G.J. Kearley, J. Tomkinson, A. Navarro, J.J.L. González, M.F. Gómez, Chem. Phys. 216 (1997) 216.

[47] I. Reva, S. Stepanian, L. Adamowicz, R. Fausto, J. Phys. Chem. A 105 (2001) 4773

[48] A.D. Becke, Phys. Rev. A 38 (1988) 3098.

[49] C.T. Lee, W.T. Yang, R.G. Parr, Phys. Rev. B 37 (1988) 785.

[50] J.H. Schachtschneider, in: Technical Report, Shell Development Co., Emeryville, CA, 1969.

[51] M. Frisch, G. Trucks, H. Schlegel, G. Scuseria, M. Robb, J. Cheeseman, V. Zakrzewski, J. Montgomery, R. Stratmann, K. Burant, S. Dapprich, J. Millam, A. Daniels, K. Kudin, M. Strain, O. Farkas, J. Tomasi, V. Barone, M. Cossi, R. Cammi, B. Mennucci, C. Pomelli, C. Adamo, S. Clifford, J. Ochterski, G. Petersson, P. Ayala, Q. Cui, K. Morokuma, D. Malick, A. Rabuck, K. Raghavachari, J. Foresman, J. Cioslowski, J. Ortiz, A. Baboul, B. Stefanov, G. Liu, A. Liashenko, P. Piskorz, I. Komaromi, R. Gomperts, R. Martin, D. Fox, T. Keith, M. Al-Laham, C. Peng, A. Nanayakkara, M. Challacombe, P. Gill, B. Johnson, W. Chen, M. Wong, J. Andres, C. Gonzalez, M. Head-Gordon, S. Replogle, J. Pople, Gaussian 98, Revision A.9, Gaussian Inc., Pittsburgh, PA, 1998.

[52] S.E. Stein, in: D.J. Linstrom, W.G. Mallard (Eds.), NIST chemistry webbook, NIST Standard Reference Datebase, National Institute of Standard Technology, Gaithersburg, 2003 (No. 69), http: //webbook.NIST.gov.

[53] J. Vázquez, J.J.L. González, F. Marquez, J.E. Boggs, J. Raman Spectrosc. 29 (1998) 547.

[54] F. Lahmani, N. Ivanoff, Tetrahedron Lett. (1967) 3913.

[55] F. Lahmani, N. Ivanoff, J. Phys. Chem. 76 (1972) 2245.

[56] V.B. Lobastov, R. Srinivasan, B.M. Goodson, Ch.-Y. Ruan, J.S. Feenstra, A.H. Zewail, J. Phys. Chem. A 105 (2001) 11159.

[57] N. Kanamaru, Bull. Chem. Soc. Jpn 71 (1998) 2299.

[58] W. Domcke, A.L. Sobolewski, C. Woywod, Chem. Phys. Lett. 203 (1993) 220.

[59] A.L. Sobolewski, C. Woywod, W. Domcke, J. Chem. Phys. 98 (1993) 5627.

[60] E.T. Sevy, M.A. Muyskens, S.M. Rubin, G.W. Flynn, J.T. Muckerman, J. Chem. Phys. 112 (2000) 5829.

[61] J.D. Chesko, D. Stranges, A.G. Suits, Y.T. Lee, J. Chem. Phys. 103 (1995) 6290. 